\title{
Cloud Phase and Relative Humidity Distributions over the Southern Ocean in Austral Summer Based on In Situ Observations and CAM5 Simulations ${ }^{\mathscr{a}}$
}

\author{
JoHn J. D’ALESSANDRO a AND Minghui DiAO \\ Department of Meteorology and Climate Science, San Jose State University, San Jose, California
}

\section{Chenglai Wu}

Department of Atmospheric Science, University of Wyoming, Laramie, Wyoming, and International Center for Climate and Environment Sciences, Institute of Atmospheric Physics, Chinese Academy of Sciences, Beijing, China

\section{XIAOHONG LIU}

Department of Atmospheric Science, University of Wyoming, Laramie, Wyoming

\author{
JORGEN B. JENSEN AND BRITTON B. STEPHENS \\ National Center for Atmospheric Research, Boulder, Colorado
}

(Manuscript received 15 April 2018, in final form 8 February 2019)

\begin{abstract}
Cloud phase and relative humidity $(\mathrm{RH})$ distributions at $-67^{\circ}$ to $0^{\circ} \mathrm{C}$ over the Southern Ocean during austral summer are compared between in situ airborne observations and global climate simulations. A scaleaware comparison is conducted using horizontally averaged observations from 0.1 to $50 \mathrm{~km}$. Cloud phase frequencies, RH distributions, and liquid mass fraction are found to be less affected by horizontal resolutions than liquid and ice water content (LWC and IWC, respectively), liquid and ice number concentrations $\left(\mathrm{Nc}_{\text {liq }}\right.$ and $\mathrm{Nc}_{\text {ice }}$, respectively), and ice supersaturation (ISS) frequency. At $-10^{\circ}$ to $0{ }^{\circ} \mathrm{C}$, observations show $27 \%-$ $34 \%$ and $17 \%-37 \%$ of liquid and mixed phases, while simulations show $60 \%-70 \%$ and $3 \%-4 \%$, respectively. Simulations overestimate (underestimate) $\mathrm{LWC}$ and $\mathrm{Nc}_{\text {liq }}$ in liquid (mixed) phase, overestimate $\mathrm{Nc}_{\text {ice }}$ in mixed phase, underestimate IWC in ice and mixed phases, and underestimate (overestimate) liquid mass fraction below (above) $-5^{\circ} \mathrm{C}$, indicating that observational constraints are needed for different cloud phases. $\mathrm{RH}$ frequently occurs at liquid saturation in liquid and mixed phases for all datasets, yet the observed $\mathrm{RH}$ in ice phase can deviate from liquid saturation by up to $20 \%-40 \%$ at $-20^{\circ}$ to $0^{\circ} \mathrm{C}$, indicating that the model assumption of liquid saturation for coexisting ice and liquid is inaccurate for low liquid mass fractions $(<0.1)$. Simulations lack RH variability for partial cloud fractions (0.1-0.9) and underestimate (overestimate) ISS frequency for cloud fraction $<0.1(\geq 0.6)$, implying that improving RH subgrid-scale parameterizations may be a viable path to account for small-scale processes that affect RH and cloud phase heterogeneities. Two sets of simulations (nudged and free-running) show very similar results (except for ISS frequency) regardless of sample sizes, corroborating the statistical robustness of the model-observation comparisons.
\end{abstract}

Supplemental information related to this paper is available at the Journals Online website: https://doi.org/10.1175/JCLI-D-180232.s1.

\footnotetext{
${ }^{a}$ Current affiliation: Cooperative Institute for Mesoscale Meteorological Studies and School of Meteorology, University of Oklahoma, Norman, Oklahoma.
}

Corresponding author: Minghui Diao, minghui.diao@sjsu.edu

\section{Introduction}

Clouds over the Southern Ocean are an essential component controlling the energy budget over the region and have an annual mean spatial fraction around $80 \%-90 \%$ (e.g., Kay et al. 2012; McCoy et al. 2014a; Matus and L'Ecuyer 2017). Climate models show large deficiencies in simulating radiative fluxes in the Southern Ocean region $\left(\sim 50^{\circ}-80^{\circ} \mathrm{S}\right)$ and often underestimate reflected shortwave radiation on the order of $10 \mathrm{~W} \mathrm{~m}^{-2}$ (e.g., BodasSalcedo et al. 2014; Li et al. 2013; Kay et al. 2012). This 
is in part due to the fact that climate models (e.g., Trenberth and Fasullo 2010; Kay et al. 2016a; BodasSalcedo et al. 2016; Kay et al. 2016b; Cesana and Chepfer 2013; Wang et al. 2018) as well as higher-resolution regional models (e.g., Huang et al. 2014, 2015) generally show lower cloud fraction and less supercooled liquid water (SLW; i.e., liquid water existing at temperatures below $0^{\circ} \mathrm{C}$ ) than the observations in the middle and high southern latitudes. The amount of SLW plays a critical role in determining cloud radiative forcing (e.g., Ceppi et al. 2014; Lawson and Gettelman 2014; Shupe and Intrieri 2004), cloud feedbacks (e.g., Gettelman and Sherwood 2016; Tsushima et al. 2006; McCoy et al. 2014b), and equilibrium climate sensitivity (e.g., Tan et al. 2016; Frey and Kay 2018). The fundamental mechanism of a negative cloud phase feedback due to ice to liquid transition under surface heating was proposed by Mitchell et al. (1989). Additional considerations need to be made for mixed-phase clouds (MPCs) by characterizing the mass fractions of ice and liquid phases as well as their degree of mixing, which can both substantially alter the radiation budget (Sun and Shine 1994).

Commonly referred to as the Wegener-BergeronFindeison (WBF) process, when ice particles and SLW droplets coexist, ice particles grow at the expense of neighboring supercooled liquid droplets, given that the equilibrium water vapor partial pressure $e$ is less than the saturation vapor pressure with respect to liquid $\left(\mathrm{es}_{\mathrm{liq}}\right)$ and greater than the saturation vapor pressure with respect to ice $\left(\mathrm{es}_{\text {ice }}\right)$ (Wegener 1911; Bergeron 1928, 1935, Findeisen 1938, 1940). Ambient relative humidity (RH) has large impacts on cloud phase transition and evolution, and therefore quantifying $\mathrm{RH}$ conditions becomes a key step for understanding the existence of SLW. Generally speaking, when vapor diffusion effectively equilibrates the vapor pressure between liquid and ice phases, the local RH reaches a steady state around liquid saturation. This feature is frequently shown by in situ observations on the horizontal scales of $\sim 100 \mathrm{~m}$ (Korolev and Isaac 2006) and cloud-resolving model simulations (Fan et al. 2011). Such an assumption of liquid saturation for in-cloud $\mathrm{RH}$ when ice and liquid coexist is also used in the parameterization of mixedphase stratiform clouds (Rotstayn et al. 2000), which has been adopted in several global climate models (GCMs), including the Community Atmosphere Model, version 5 (CAM5) (Gettelman et al. 2010; Gettelman and Morrison 2015; Morrison and Gettelman 2008), the European Centre for Medium-Range Weather Forecasts (ECMWF) model (Forbes and Ahlgrimm 2014), and the atmospheric component of the Geophysical Fluid Dynamics Laboratory (GFDL) coupled GCMs, CM2 (Anderson et al. 2004) and CM3 (Donner et al. 2011).
Previously Fu and Hollars (2004) compared the incloud water vapor parameterizations with 1-s in situ observations in the Arctic. However, the RH conditions as well as other cloud microphysical properties in MPCs have not been examined and compared for various scales of observations from subkilometer to tens and hundreds of kilometers.

Validating simulated cloud properties and processes within climate models is crucial as many uncertainties still remain in predicting cloud feedbacks on climatic time scales (Gettelman and Sherwood 2016). Adjusting the parameterized phase partitioning of cloud liquid and ice can either increase or decrease the climate sensitivity parameter when introducing surface temperature perturbations ( $\mathrm{Li}$ and Le Treut 1992). Tan et al. (2016) constrained the mean state of phase partitioning in the Community Earth System Model (CESM, of which CAM is a component) simulations using satellite observations and found an increase in equilibrium climate sensitivity by up to $1.3 \mathrm{~K}$ with a doubling of $\mathrm{CO}_{2}$, resulting from a weakened negative cloud phase feedback. Frey and Kay (2018) also found a 1.5-K increase in equilibrium climate sensitivity, partly due to reduced negative cloud phase feedback over the Southern Ocean when decreasing the prescribed cloud ice fraction in the total water detrained from shallow convection (Kay et al. 2016a). McCoy et al. (2014b) showed increasing upwelling shortwave radiation due to liquid replacing ice and increasing optical depths as a result of $1-\mathrm{K}$ tropospheric warming. Climate models were also reported to have difficulties capturing low-level clouds in the cold sector of midlatitude cyclones, potentially due to the prevalence of boundary layer clouds being commonly associated with large-scale subsidence in these regions (Govekar et al. 2014; Bodas-Salcedo et al. 2014), which highlights the importance of local processes relative to large-scale processes, such as cyclonic activity.

Previously, given the scarcity of in situ observations over the Southern Ocean, only a few studies analyzed in situ observations (e.g., Huang et al. 2015; Ahn et al. 2017; Chubb et al. 2013; Huang et al. 2017; Ovarlez et al. 2002; Morrison et al. 2010; Jensen et al. 2000) and none of them was directly compared with GCM simulations. In fact, most studies relied on spaceborne observations to analyze cloud microphysical properties (e.g., Bodas-Salcedo et al. 2012, 2014, 2016; McCoy et al. 2016; Cesana et al. 2015; Hu et al. 2010; Morrison et al. 2011; Huang et al. 2012a,b; Matus and L'Ecuyer 2017) and RH distributions (Lamquin et al. 2012; Gettelman et al. 2006; Kahn et al. 2009; Spichtinger et al. 2003) over this remote region. Although the satellite data provide useful information for climatological purposes, their phase determination often includes a large amount of 
undefined-phase clouds, and various active and passive detection approaches have large differences in their sampling, accuracy, sensitivity, and assumptions (Nasiri and Kahn 2008; Kahn et al. 2011; Cho et al. 2009; Hu et al. 2009; Chylek et al. 2006; Naud et al. 2006; Riedi et al. 2010). For example, the Cloud-Aerosol Lidar and Infrared Pathfinder Satellite Observations (CALIPSO) cloud phase identification is mostly affected by the cloud top (Cesana et al. 2016); the Moderate Resolution Imaging Spectroradiometer (MODIS) cloud-top phase product has limited accuracy from $-25^{\circ}$ to $-5^{\circ} \mathrm{C}$ (Morrison et al. 2011); the Polarization and Directionality of Earth Reflectances (POLDER) spaceborne instrument uses visible and near-infrared channels, and has difficulties detecting very thin clouds and cloud edges as well as defining phases for multilayer clouds (Goloub et al. 2000; Riedi et al. 2001). In addition, it is difficult for satellites to retrieve high-resolution RH distributions relevant to cloudscale microphysical processes. For example, the NASA Atmospheric Infrared Sounder (AIRS)/Advanced Microwave Sounding Unit (AMSU) temperature and water vapor retrievals have vertical and horizontal resolutions of $1-3 \mathrm{~km}$ and $45 \mathrm{~km} \times 45 \mathrm{~km}$, respectively, and have differences of $\sim 1-2.5 \mathrm{~K}$ in temperature and $\sim 20 \%-60 \%$ in water vapor compared with in situ observations (Diao et al. 2013). In contrast, $1-\mathrm{Hz}$ in situ measurements obtained from research aircraft have horizontal resolutions ranging from 100 to $250 \mathrm{~m}$. Previously, in situ measurements of RH and cirrus cloud microphysical properties were analyzed for temperatures $<-40^{\circ} \mathrm{C}$ over Punta Arenas, Chile (Ovarlez et al. 2002; Gayet et al. 2006), yet a comprehensive analysis for $-40^{\circ}$ to $0^{\circ} \mathrm{C}$ is still missing.

The purpose of this study is to examine the distributions of cloud phases and RH during austral summer over the Southern Ocean based on in situ observations, and compare with CAM5 simulations. Observations from the National Science Foundation (NSF) $\mathrm{O}_{2} / \mathrm{N}_{2}$ Ratio and $\mathrm{CO}_{2}$ Airborne Southern Ocean Study (ORCAS) (Stephens et al. 2018) took place during the austral summer, a time at which a deep circumpolar storm track often occurs (Hoskins and Hodges 2005). Effects of horizontal spatial resolution on the analyses are examined by spatially averaging observations from subkilometer to tens of kilometers. A series of model-observation comparisons have been conducted, including cloud phase distributions at various temperatures, cloud microphysical properties [i.e., liquid and ice water content (LWC and IWC, respectively), liquid and ice number concentration $\left(\mathrm{Nc}_{\text {liq }}\right.$ and $\mathrm{Nc}_{\text {ice }}$, respectively)] for three cloud phases, and $\mathrm{RH}$ frequency distributions. The prerequisite condition of ice particle formation-ice supersaturation (ISS $=$ RHi $-100 \%$ ) - has also been compared between observations and simulations from $-67^{\circ}$ to $0^{\circ} \mathrm{C}$. These comparisons will help to improve the representations of cloud thermodynamic phases and to reduce bias of the amount of SLW over the Southern Ocean in GCM simulations.

\section{Dataset and experimental setup}

\section{a. In situ observations}

This study uses 1-Hz airborne measurements from the NSF Gulfstream-V (GV) research aircraft during the ORCAS campaign (Stephens 2017). ORCAS took place from 15 January to 28 February 2016, sampling over the Southern Ocean from $30^{\circ}$ to $75^{\circ} \mathrm{S}$ and from $50^{\circ}$ to $92^{\circ} \mathrm{W}$. The ORCAS campaign conducted 19 research flights, and 18 of them reported final data with $\sim 95 \mathrm{~h}$ of flight time in total. Details on flight objectives and analyses can be found in Stephens et al. (2018). Observations in this study are restricted to temperatures $<0^{\circ} \mathrm{C}$ to exclude warm cloud measurements (i.e., clouds with no ice or SLW). The total flight time at $-40^{\circ}$ to $0^{\circ} \mathrm{C}$ is $40 \mathrm{~h}$. Incloud sampling times for $-10^{\circ}$ to $0^{\circ},-20^{\circ}$ to $-10^{\circ},-30^{\circ}$ to $-20^{\circ},-40^{\circ}$ to $-30^{\circ}$, and $<-40^{\circ} \mathrm{C}$ are $3.2,1.2,1.2,0.73$, and $1.3 \mathrm{~h}$, respectively. The flights in the ORCAS campaign often sampled cyclones and frontal systems associated with strong westerly flow around the Drake Passage and nearby regions. These synoptic-scale conditions coupled with cool ocean surface led to frequent cloud cover over the ORCAS flight domain, including many cases of low-level and midlevel stratus and stratocumulus. Multilayer stratus and single-layer stratocumulus have been frequently observed in several flights.

Temperature $T$ was measured using a Rosemount temperature probe, having an accuracy and precision of $\pm 0.3 \mathrm{~K}$ and $0.01 \mathrm{~K}$, respectively. Water vapor measurements were obtained from the $25-\mathrm{Hz}$ Vertical Cavity Surface Emitting Laser (VCSEL) hygrometer (Zondlo et al. 2010), which has an accuracy and precision of $\sim 6 \%$ and $\leq 1 \%$, respectively. Final data of water vapor mixing ratio and temperature were reported at $1 \mathrm{~Hz}$. Two sets of $\mathrm{RH}$ data are calculated, $\mathrm{RH}$ with respect to liquid (RHliq) and ice (RHi), based on Murphy and Koop (2005) that derived es liq $_{\text {liq }}$ and es ice $_{\text {from a synthesis of }}$ laboratory results. For temperatures relevant in this study at $-69^{\circ}$ to $0^{\circ} \mathrm{C}$, the uncertainties in RHi range from $7.5 \%$ to $6.5 \%$, and the uncertainties in RHliq range from $10.4 \%$ to $6.4 \%$, respectively. Because of the combined uncertainties from water vapor and temperature measurements, the observed RHliq greater than liquid saturation is set to be equal to $100.01 \%$ (processed for 
$7745 \mathrm{~s}$ of observations). Such restriction does not alter the number of occurrences for liquid or ice supersaturation.

Cloud particle measurements were made by the Fast 2-Dimensional Optical Array Cloud probe (Fast-2DC) and the Cloud Droplet Probe (CDP). The CDP measures particles ranging from 2 to $50 \mu \mathrm{m}$. The Fast-2DC detects particles from 62.5 to $1600 \mu \mathrm{m}$ in diameter (excluding the first two bins), and larger particles can be mathematically reconstructed up to $3200 \mu \mathrm{m}$. The mass concentrations for Fast-2DC are calculated based on Brown and Francis (1995). We define in-cloud conditions as having either of these two conditions: 1) CDP measurements report both number concentration $>0.03 \mathrm{~cm}^{-3}$ and derived mass concentration $>3.98 \times 10^{-4} \mathrm{~g} \mathrm{~m}^{-3}$ and 2) Fast-2DC measurements detect at least one particle in a second, and its minimum derived mass concentration was $4.68 \times 10^{-5} \mathrm{~g} \mathrm{~m}^{-3}$ in the ORCAS campaign. The rest of the measurements are defined as clear-sky conditions. The CDP threshold was chosen in order to minimize the impacts of giant aerosols, which were determined by the relationships between number and mass concentrations (Fig. 1).

\section{b. Global climate model simulations}

The model used here is CAM5, which is the atmospheric component of NCAR CESM. A detailed description of CAM5 can be found in Neale et al. (2012). Of particular relevance to this study are the representations of cloud macrophysics (Park et al. 2014), cloud microphysics (Morrison and Gettelman 2008), and shallow convection (Park and Bretherton 2009). Cloud microphysics is coupled with a modal aerosol module (MAM) (Liu et al. 2012) for aerosol-cloud interactions. The version of MAM with three modes (MAM3) is adopted here. Cloud droplets can form via the activation of aerosols (Abdul-Razzak and Ghan 2000). Ice crystals can form via the homogeneous nucleation of sulfate aerosol and/or heterogeneous nucleation of dust aerosol (Liu and Penner 2005; Liu et al. 2007). Hallet-Mossop ice multiplication (secondary ice production) due to accretion of drops by snow is included following Cotton et al. (1986).

Results from in situ observations are compared with two types of CAM5 simulations: the nudged simulation and the free-running simulation. Both simulations were run with a finite-volume dynamical core (Lin 2004), a horizontal spatial resolution of $0.47^{\circ} \times 0.63^{\circ}$, a pressure top of $30 \mathrm{hPa}$, and a time step of $1800 \mathrm{~s}$. The number of vertical levels for nudged and free-running simulations is 56 and 30, respectively. The nudged CAM5 simulation (hereafter "CAM-collocated") was forced to represent meteorological conditions (3D temperature and wind speed) according to the NASA Goddard
Earth Observing System Model, version 5 (GEOS-5), data (Lamarque et al. 2012), and the output were saved along the aircraft flight track. The detailed nudging method is described in Wu et al. (2017) and Zhang et al. (2014). The free-running CAM5 simulation (hereafter "CAM-domain") was run with prescribed climatological sea surface temperature and sea ice extent. The simulation covered the duration of the ORCAS campaign with a 1-yr spinup time and 6-hourly output (0000, 0600, 1200, and 1800 UTC). Outputs with the nearest time to the midpoint time stamp of each research flight are selected, which forms a composite CAM-domain dataset with 18 model outputs, restricted to the horizontal regions $\left(50^{\circ}-92^{\circ} \mathrm{W}, 30^{\circ}-75^{\circ} \mathrm{S}\right)$ and altitudes (pressure $p>176.38 \mathrm{hPa}$ ) comparable to the flight domain.

For analyses of cloud microphysical properties, the model output variables used are "LWC," "IWC," "NUMLIQ" $\left(\mathrm{Nc}_{\text {liq }}\right)$, and "NUMICE" $\left(\mathrm{Nc}_{\text {ice }}\right)$, all of which are gridbox-average quantities. When defining in-cloud conditions, either the value of LWC or IWC being greater than $4.68 \times 10^{-5} \mathrm{~g} \mathrm{~m}^{-3}$ is considered to be in-cloud condition. The rest is defined as clear-sky condition, with IWC and LWC in clear-sky conditions set to be zero. Such definition is consistent with the minimum value of mass concentration detected by in situ observations. The calculation of RHi and RHliq is based on Goff and Gratch (1946) in the CAM5 simulations. Since the observations calculate saturation vapor pressures based on equations from Murphy and Koop (2005), both RHi and RHliq values have differences within $\pm 0.3 \%$ compared with those calculated from Goff and Gratch (1946).

\section{c. Spatial averaging of observations}

One of the main challenges for comparing in situ observations and global climate model simulations is their differences in spatial resolution. To address this inherent problem, $1-\mathrm{Hz}$ airborne observations were averaged over various time intervals: $10,25,50,100$, and $200 \mathrm{~s}$ (named as Obs-Xs). The GV aircraft true airspeed ranges from $\sim 100$ to $250 \mathrm{~m} \mathrm{~s}^{-1}$ from near surface to the upper troposphere and lower stratosphere (UT/LS), respectively. Thus, spatially averaged observations at 10-200-s intervals have horizontal resolutions of $\sim 1-20 \mathrm{~km}$ near the surface and $\sim 2.5-$ $50 \mathrm{~km}$ at the UT/LS (see Table S1 in the online supplemental material). Such averaging mostly applies to the horizontal direction since aircraft true airspeed is one to two orders of magnitude higher in the horizontal direction than in the vertical direction. No spatial averaging was applied to CAM-collocated or CAM-domain data, and they have horizontal 

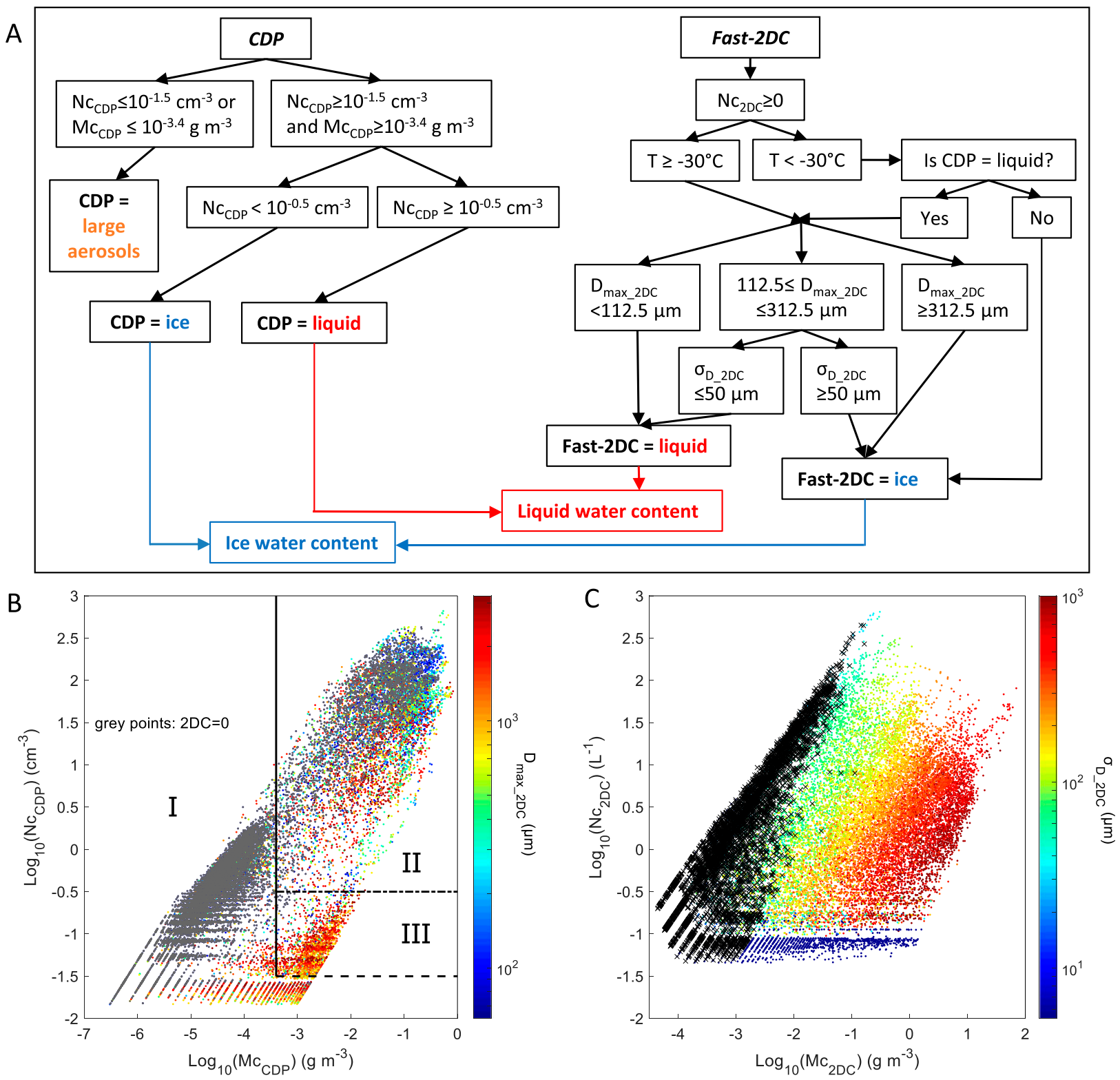

FIG. 1. Cloud phase identification method used in this work. (a) A diagram for identifying ice and liquid phase samples from two probes separately, and the total IWC and LWC stand for the sum of IWC and LWC from two probes, respectively. (b) Number vs mass concentrations of CDP probe $\left(\mathrm{Nc}_{\mathrm{CDP}}\right.$ and $\mathrm{Mc}_{\mathrm{CDP}}$, respectively) color coded by $D_{\max \_2 \mathrm{DC}}$. Gray dots show $\mathrm{Nc}_{2 \mathrm{DC}}=0$. Sections I, II, and III are defined as large aerosols, liquid droplets, and ice crystals, respectively. (c) Relationship of $\mathrm{Nc}_{2 \mathrm{DC}}$ and $\mathrm{Mc}_{2 \mathrm{DC}}$, color coded by the standard deviation of $1-\mathrm{Hz}$ particle size distribution $\sigma_{D \_2 \mathrm{DC}}$. Black markers highlight where the Fast-2DC measurements are identified as liquid droplets.

resolutions of $14-70 \mathrm{~km}$ from higher to lower latitudes $\left(75^{\circ}-30^{\circ} \mathrm{S}\right)$, comparable to the Obs-100s and Obs-200s data at $10-50-\mathrm{km}$ resolutions, respectively.

Cloud fraction for observations is calculated as the number of $1-\mathrm{Hz}$ in-cloud data divided by the total number of $1-\mathrm{Hz}$ data during the averaging time interval ( $\Delta$ time). Temperature, RHi, RHliq, LWC, IWC, $\mathrm{Nc}_{\text {liq }}$, and $\mathrm{Nc}_{\text {ice }}$ are averaged over the entire time interval, which correspond well with the grid-average variables from CAM5. A "moving average" method is applied for each 1-Hz sample by averaging between $\pm N$ seconds or between $-N$ and $N+1 \mathrm{~s}$, where $N$ equals $(\Delta$ time -1$) / 2$ or $(\Delta$ time $) / 2$ for odd or even $\Delta$ time values, respectively. If more than $10 \%$ of a time interval reports missing data, that sample would be discarded. 


\section{Results}

\section{a. Definition of three cloud phases}

Cloud phase is defined by the mass fraction of LWC with respect to cloud water content (CWC, i.e., $\mathrm{CWC}=$ IWC + LWC), similar to the definition used in Korolev et al. (2003). A given cloud sample is considered ice phase at LWC/CWC $\leq 0.1$, mixed phase at $0.1<\mathrm{LWC} / \mathrm{CWC}<0.9$, and liquid phase at $\mathrm{LWC} / \mathrm{CWC} \geq 0.9$. This definition is applied to both observations and simulations.

Figure 1a shows a diagram of the cloud phase identification method. All cloud hydrometeors below $-40^{\circ} \mathrm{C}$ are considered ice. LWC and IWC are derived from two cloud probes by combining their ice and liquid measurements, respectively. After removing large aerosols (section I in Fig. 1a), samples detected by CDP are considered liquid if number concentration $\left(\mathrm{Nc}_{\mathrm{CDP}}\right) \geq 10^{-0.5} \mathrm{~cm}^{-3}$ (i.e., $0.316 \mathrm{~cm}^{-3}$ ), otherwise they are considered ice. At $-30^{\circ}$ to $0^{\circ} \mathrm{C}, 2 \mathrm{DC}$ measurements are considered ice when the maximum diameter $D_{\text {max } \_ \text {DC }}>312.5 \mu \mathrm{m}$ within a $1-\mathrm{Hz}$ measurement by 64 diodes. They are considered liquid for $D_{\text {max_2DC }}<112.5 \mu \mathrm{m}$. For $112.5 \leq$ $D_{\text {max_2DC }} \leq 312.5 \mu \mathrm{m}$, the 2DC sample is considered liquid when the $1-\mathrm{Hz}$ standard deviation of particle diameters $\sigma_{D \_2 \mathrm{DC}} \leq 50 \mu \mathrm{m}$, while the rest of the samples at this $D_{\text {max } 2 \text { DC }}$ range are considered ice. At $-40^{\circ}$ to $-30^{\circ} \mathrm{C}$, a $2 \mathrm{DC}$ sample can only be identified as liquid if the concurrent CDP measurement is liquid, as well as the aforementioned criteria for liquid phase are satisfied. Otherwise, that 2DC sample is identified as ice. These key thresholds are illustrated in the relationships of number versus mass concentrations (Figs. 1b,c). The fundamental concept of using $D_{\text {max_2DC }}$ and $\sigma_{D \_2 \mathrm{DC}}$ is similar to the method in McFarquhar et al. (2007), but the thresholds have been further adjusted for the instrumentation on GV aircraft, and verified by examining the 2DC imagery and comparing with measurements from the King and Rosemount Icing Detector (RICE) probes. In addition, a slightly different cloud phase identification method without the temperature threshold of $-30^{\circ} \mathrm{C}$ for the $2 \mathrm{DC}$ probe was used to analyze an earlier version (April 2018) of the ORCAS data (D'Alessandro 2018). Sensitivity tests show differences mostly within $10 \%$ for cloud phase occurrence frequencies, when examining various thresholds of $D_{\text {max_2DC }}, \sigma_{\mathrm{D} \_2 \mathrm{DC}}$, $\mathrm{Nc}_{\mathrm{CDP}}$, etc. (see Fig. $\mathrm{S} 1$ in the online supplemental material)

Time series in Research Flight (RF) 17 and 03 illustrate two typical model-observation discrepancies, that is, simulations misidentifying liquid and mixed phases as ice phase (Fig. 2) and misidentifying ice phase as liquid and mixed phases (Fig. 3). Cloud phases are highlighted by colored markers below the abscissa (Figs. 2d,e, 3d,e). Exemplary Fast-2DC images show good agreement with the cloud phases being identified (Figs. $2 \mathrm{~g}, 3 \mathrm{~g}$ ). In addition, when SLW droplets are identified, the King probe often reports LWC $>0.1 \mathrm{~g} \mathrm{~m}^{-3}$ (Figs. 2d, 3d). The King probe infers LWC by the power required to evaporate cloud droplets after their impact with the hotwire (King et al. 1978), which may involve biases in LWC when sampling droplets larger than $100 \mu \mathrm{m}$ (Biter et al. 1987) and/or ice particles (Baumgardner et al. 2017). An additional verification of the cloud phase identification method is conducted by comparing with the RICE probe data (Fig. S2).

$\mathrm{RH}$ values are less variable in averaged observation data (Figs. 2a-c, 3a-c), and compare well with simulations for liquid and mixed phases. However, at RF031745:00-1751: 00 UTC, CAM-collocated data show RHi at or above ice saturation (Fig. 3c) with coexisting liquid and ice (Fig. 3e), as opposed to the observations that are almost exclusively ice phase at ice subsaturation, potentially from sedimentation (Figs. 3b-d). The underestimated occurrences of ice subsaturation are found to be a common problem in CAM5 simulations, and will be discussed further in section $3 \mathrm{~d}$. The CDP, Fast-2DC probes, and VCSEL hygrometer all provide open-path measurements, and their data recording synchronization is within milliseconds. For occasions when liquid cloud edge does not match with liquid saturation, it could be due to the combined uncertainties in RHliq (i.e., $6.4 \%-10.4 \%$ ) and/or the distance between the cloud probes and the VCSEL hydrometer.

Four typical cloud phase segments are seen: 1) a homogeneous, liquid-dominant condition (e.g., RF03, 1738:401741:20 UTC), 2) a homogeneous, ice-dominant condition potentially from sedimentation (e.g., RF03, 1744:30-1752:00 UTC), 3) a relatively well-mixed segment of mixed phase (e.g., RF17, 1942:35-1943:20 UTC), and 4) a spatially heterogeneous mixed phase with a mixture of ice and liquid (e.g., RF17, 1939:15-1941:05 UTC and RF03, 1752:00-1758: 40 UTC). Separate pockets of pure ice, pure water, and a mixture of both were seen on the order of hundreds of meters based on 1-Hz data, similar to those pockets reported in Korolev et al. (2003), also known as the "conditionally" mixed-phase clouds (Korolev et al. 2017). Large spatial heterogeneities in mixed phase are consistent with those reported by several previous studies, such as the global survey of cloud thermodynamic phase on the subkilometer scales based on Hyperion imaging spectrometer onboard NASA's Earth Observer 1 (EO-1) spacecraft (Thompson et al. 2018), 20-m-horizontal-resolution satellite data of Arctic clouds (Chylek and Borel 2004), and 100-m horizontal resolution in situ and ground-based observations of midlatitude MPCs (Field et al. 2004).

\section{b. Cloud phase frequencies and characteristics}

Cloud phase occurrence frequencies are examined for all in-cloud conditions (Fig. 4), as well as CWC $\geq 0.01 \mathrm{gm}^{-3}$ 
A

Time series: Flight RF17

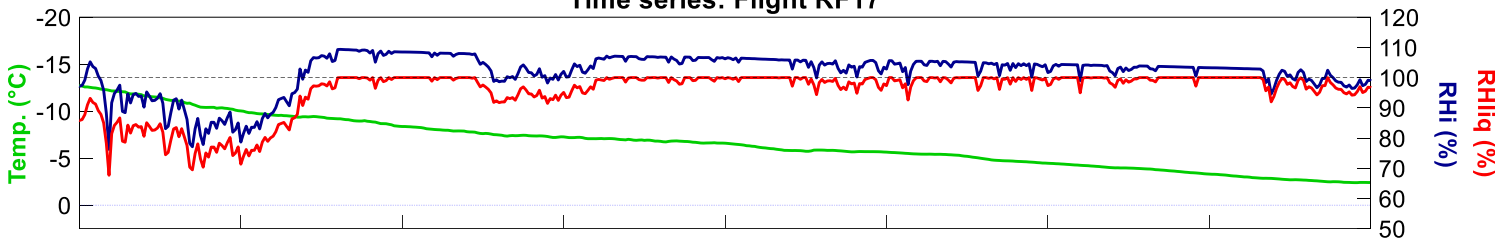

B

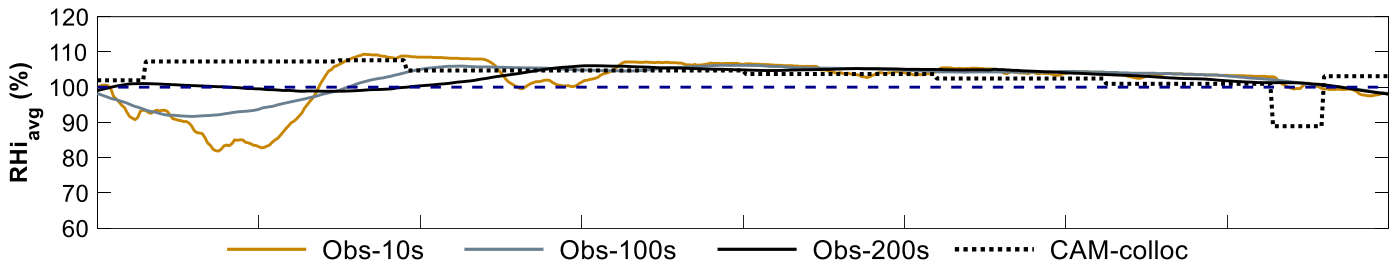

C

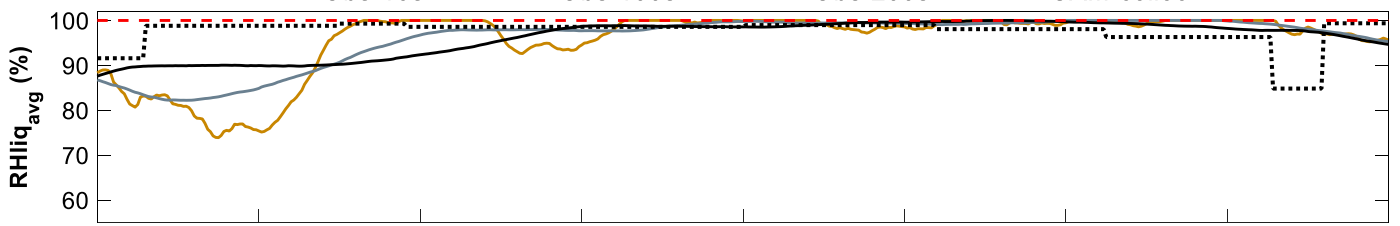

D

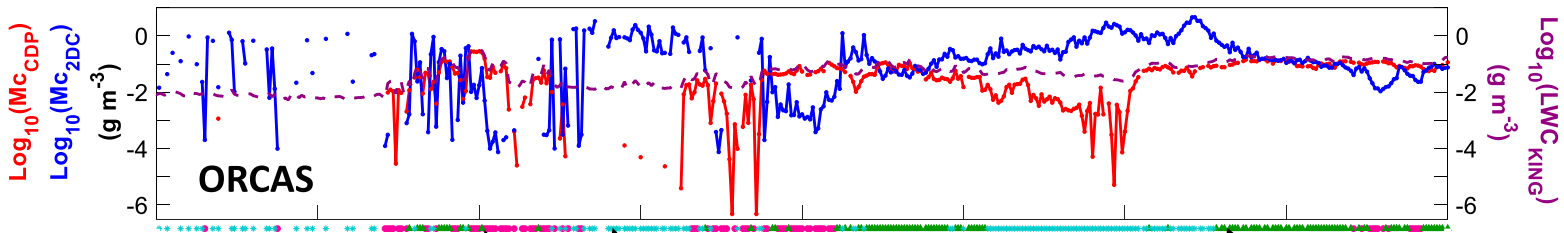

E

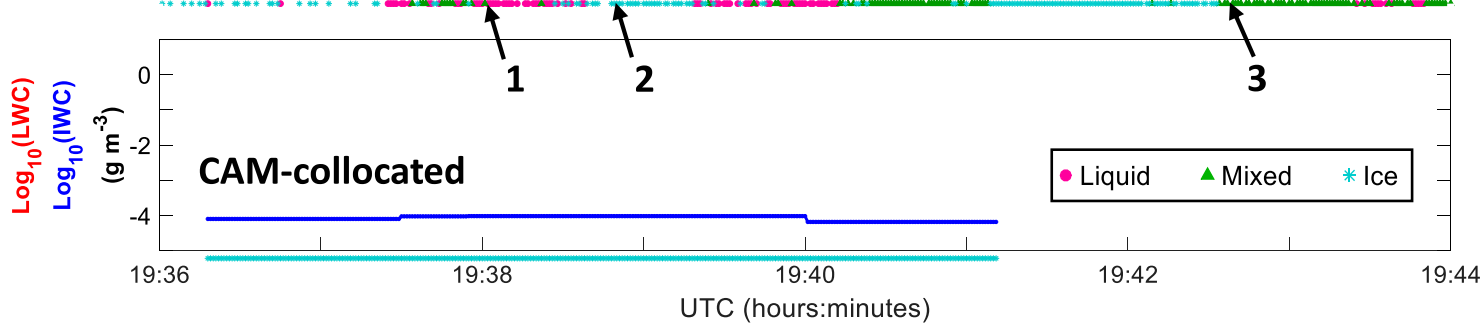

$\mathbf{F}$

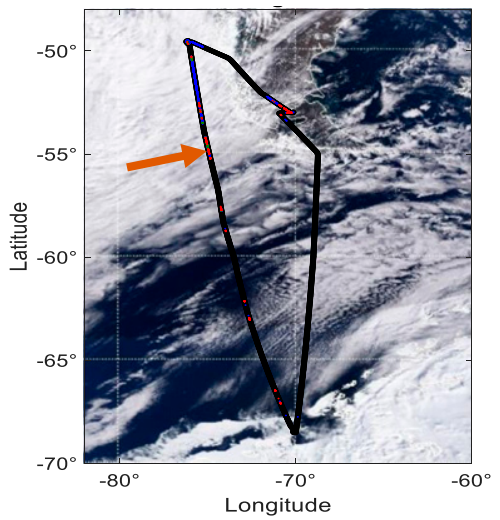

G
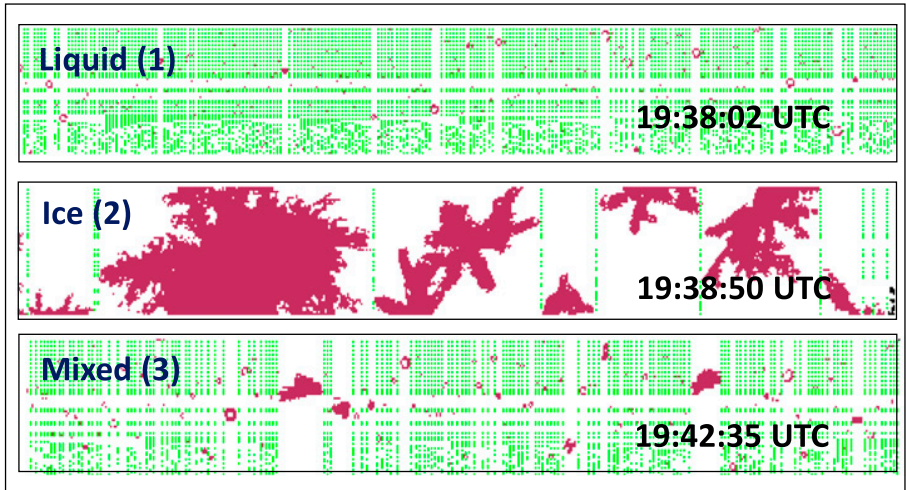

FIG. 2. An example time series during RF17 of the NSF ORCAS campaign: (a) 1-Hz observations of temperature, RHliq, and RHi, with $\mathrm{RH}=100 \%$ (dashed gray) and temperature $=0^{\circ} \mathrm{C}$ (dotted blue) highlighted; (b) RHi and (c) RHliq for various scales of observations and CAM-collocated data; (d) log-scale $\mathrm{Mc}_{\mathrm{CDP}}$ (red) and $\mathrm{Mc}_{2 \mathrm{DC}}$ (blue) and log-scale LWC measured by the King probe (purple); and (e) LWC and IWC from CAM-collocated data. In (d) and (e), cloud phases are identified by markers below the abscissa. (f) MODIS image around the flight track (black), with cloud phase highlighted in colors and an orange arrow pointing at the time series segment. The MODIS image is at 1910:00 UTC 24 Feb 2016. (g) Cloud particle imagery from the Fast-2DC probe for the three individual times noted by black arrows $1-3$ in (d), respectively. 
A

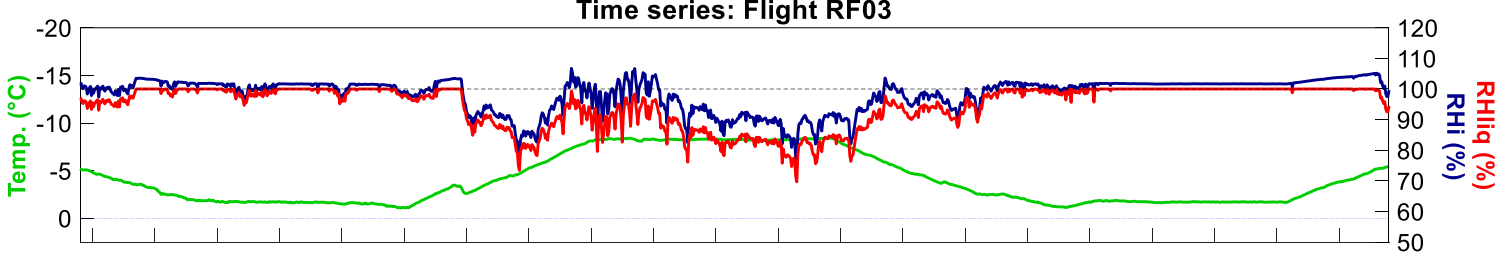

B

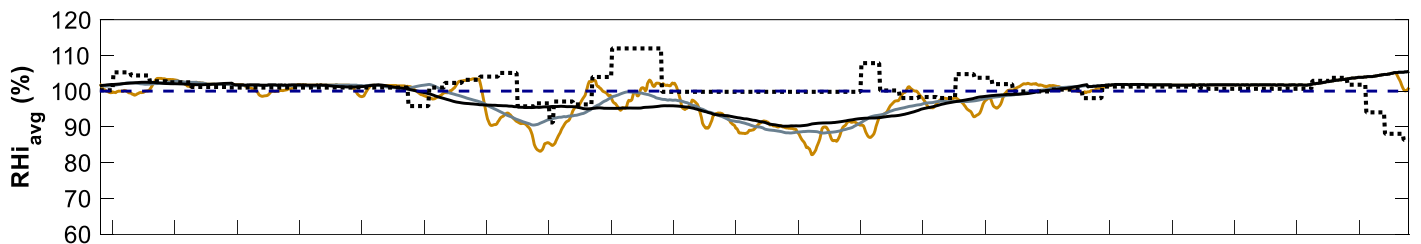

C

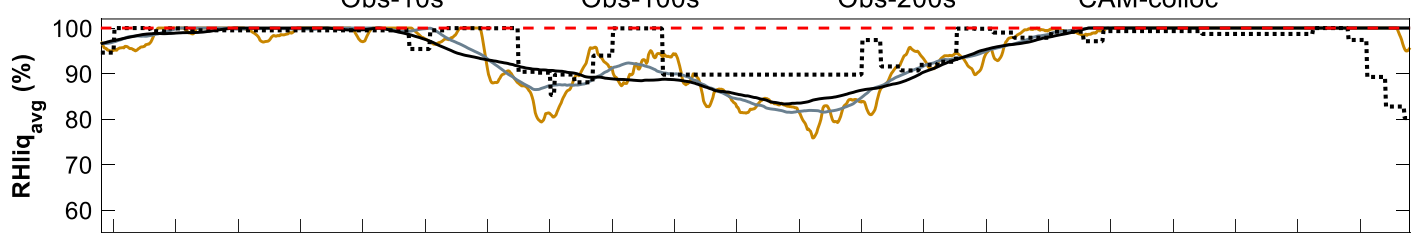

D

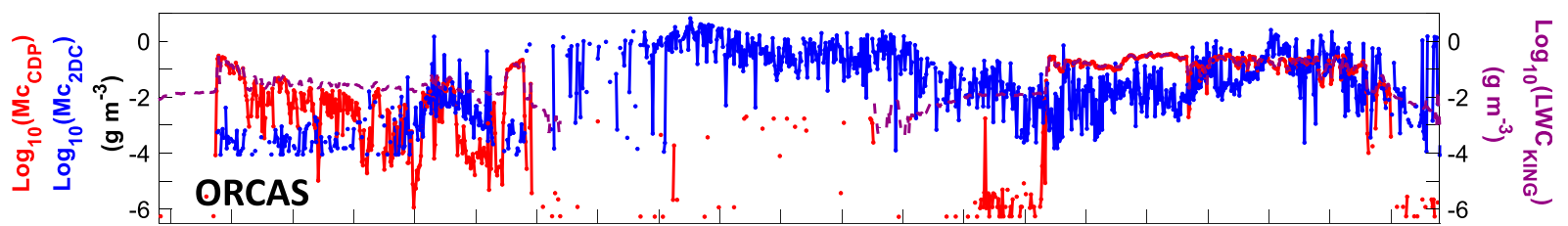

E

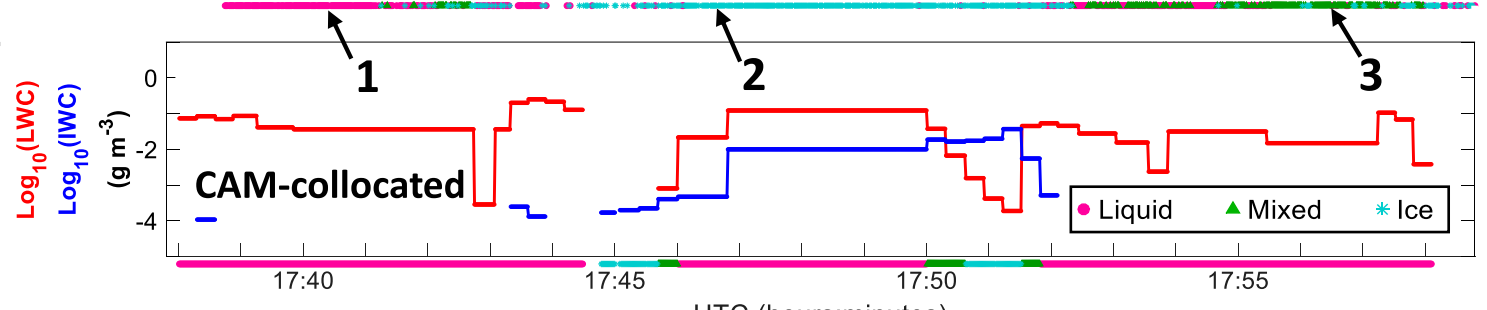

$\mathbf{F}$

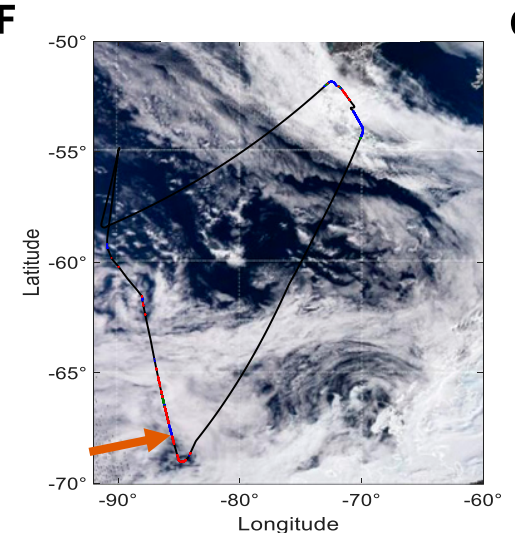

G

UTC (hours:minutes)

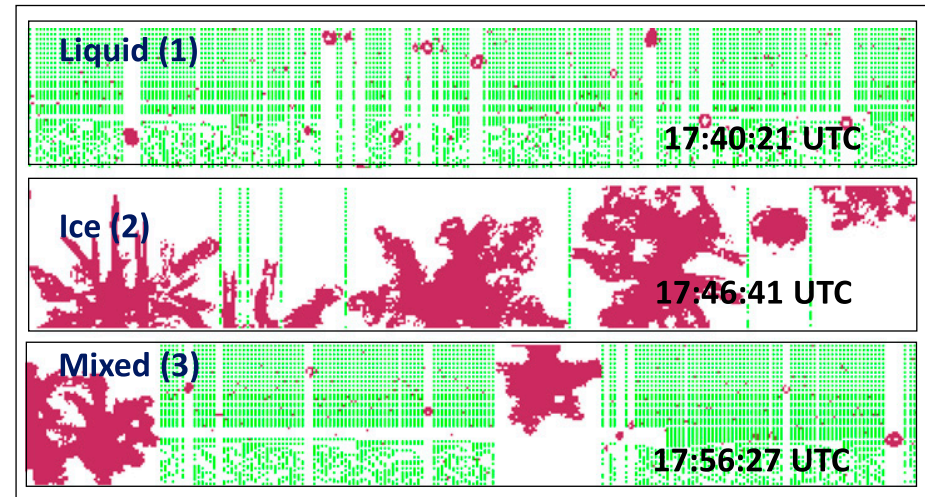

FIG. 3. As in Fig. 2, but for a time series during RF03. The MODIS image is at 1915:00 UTC 21 Jan 2016. (g) The three examples (1, 2, and 3) of Fast-2DC imagery are similar to those reported as types 1a, 2, and 1b, respectively, in Costa et al. (2017).

and cloud fraction $\geq 0.6$ (Table 1 ). More sensitivity tests using various in-cloud thresholds are shown in Figs. S3-S5. Spatially averaging $1-\mathrm{Hz}$ observations into 200 -s intervals has approximately doubled the occurrence frequency of mixed-phase samples from $17 \%$ to $37 \%$ at $-10^{\circ}$ to $0^{\circ} \mathrm{C}$ and lowered the occurrence frequencies of liquid- and ice-phase samples when restricting $\mathrm{CWC} \geq 0.01 \mathrm{~g} \mathrm{~m}^{-3}$ (Table 1). Coarser-resolution observations show more 


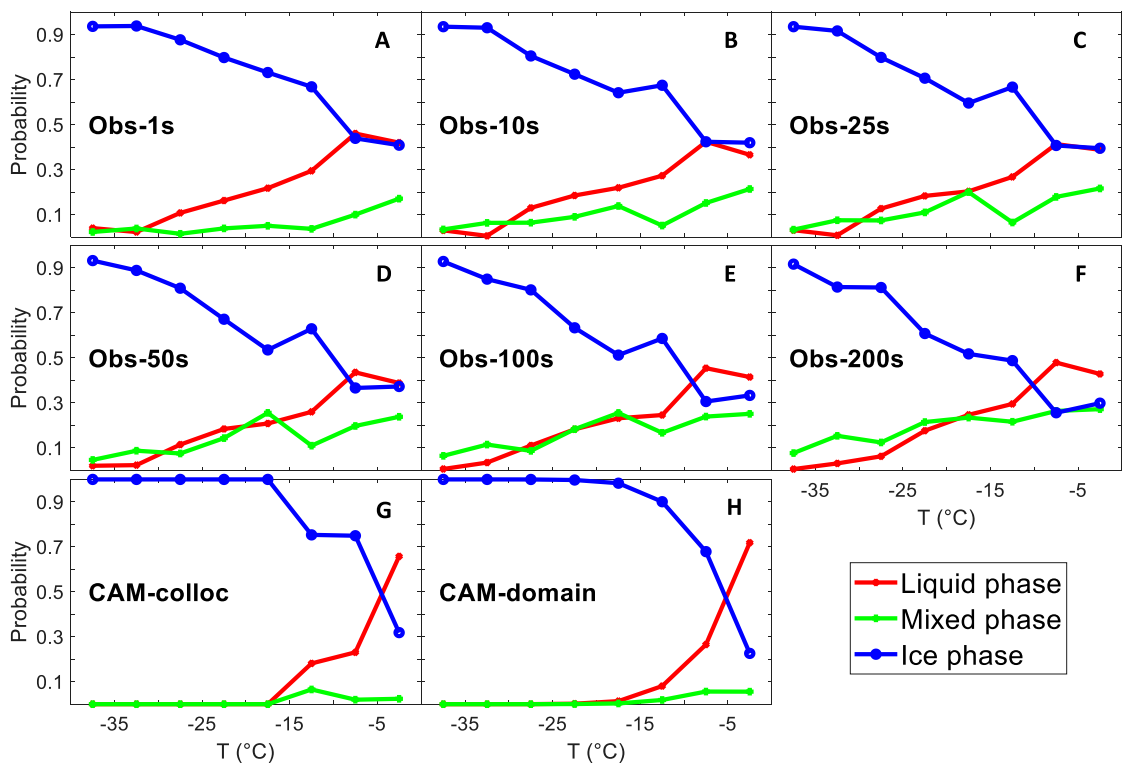

FIG. 4. Cloud phase occurrence frequency for all in-cloud conditions. Temperature is binned in $5^{\circ} \mathrm{C}$ intervals. Sensitivity tests to various in-cloud thresholds are shown in Figs. S3-S5.

"conditionally" mixed-phase samples than higherresolution data due to spatial averaging of individual cloud phase pockets, as discussed in Korolev et al. (2017). In addition, the spatial averaging leads to fewer liquid-phase samples that satisfy the condition of cloud fraction $\geq 0.6$ (i.e., $41 \%$ for Obs- 1 s and $5 \%$ for Obs200s). This is also partly due to vertical profiling of the research aircraft at low altitudes, which leads to relatively short residence time in boundary layer clouds. Total number of seconds and lengths of samples based on mean true airspeed at various temperature ranges is given in Table S2.

Compared with observations, both simulations have significantly lower frequencies of mixed-phase samples, regardless of the restrictions on in-cloud conditions (Fig. 4, Figs. S3-S5, and Table 1). For CWC $\geq$ $0.01 \mathrm{~g} \mathrm{~m}^{-3}$, from $-20^{\circ}$ to $0^{\circ} \mathrm{C}$, the Obs-200s data show $17 \%-37 \%$ of mixed phase, while both CAM-collocated and CAM-domain data show only about $1 \%-4 \%$. Interestingly, both simulations show more liquid phase samples $(60 \%-70 \%)$ compared with the Obs-200s data $(27 \%)$ from $-10^{\circ}$ to $0^{\circ} \mathrm{C}$. From $-20^{\circ}$ to $-10^{\circ} \mathrm{C}$, the CAM-collocated data also contain $53 \%$ of liquid phase, which is 3 times of that in the Obs-200s $(16 \%)$, and underestimate frequencies of ice- and mixed-phase samples. Previously, CAM5 simulations have been reported to underestimate SLW content and overproduce ice at temperatures relevant for mixed-phase conditions compared with satellite observations (e.g., Komurcu et al. 2014; Cesana et al. 2015; Kay et al. 2016b; Wang et al. 2018). Comparing these previous findings with our results on phase frequencies indicates that satellite observations may be biased to detect a layer of SLW at the top of cold clouds (e.g., Rauber and Tokay 1991) and underestimate ice-phase occurrence frequency below cloud top. It is also possible that the underestimation of SLW content in simulations is more likely attributed to underestimating mixed-phase frequencies than overestimating liquid-phase frequencies. More assessment is needed for the vertical distribution and lifetime of SLW in various cloud phases.

For the examination of liquid and ice mass partitioning, normalized frequencies of $\mathrm{LWC} / \mathrm{CWC}$ ratios are binned by $10^{\circ}$ (Fig. 5) and $5^{\circ} \mathrm{C}$ (Fig. S6) intervals from $-40^{\circ}$ to $0^{\circ} \mathrm{C}$, separated into two categories, $\mathrm{CWC} \geq 0.01 \mathrm{~g} \mathrm{~m}^{-3}$ and cloud fraction $\geq 0.6$. All of the observations and simulations show decreasing frequencies of liquid phase (i.e., $\mathrm{LWC} / \mathrm{CWC} \geq$ $0.9)$ and increasing frequencies of ice phase (i.e., $\mathrm{LWC} /$ $\mathrm{CWC} \leq 0.1$ ) with decreasing temperature, consistent with more favorable thermodynamic conditions for ice phase at lower temperatures. The threshold of $\mathrm{CWC} \geq 0.01 \mathrm{~g} \mathrm{~m}^{-3}$ is the same as that used in Korolev et al. (2003). Under this condition, the $1-\mathrm{Hz}$ observations reveal similar distributions of cloud phase occurrence frequencies to those shown in Korolev et al. (2017), which recalculated Nevzorov probe measurements initially reported by Korolev et al. (2003) inside clouds in frontal systems. Specifically, 1-Hz observations in the ORCAS campaign show similar frequencies of liquid (34\%), mixed (17\%), and ice phases $(49 \%)$ from $-10^{\circ}$ to $0^{\circ} \mathrm{C}$, comparable to $\sim 37 \%, 20 \%$, and $43 \%$ 
TABLE 1. Number of samples and occurrence frequencies of three cloud phases at various temperature ranges. The number of samples generally increases with increasing averaging scales of observation data for $\mathrm{CWC} \geq 0.01 \mathrm{~g} \mathrm{~m}^{-3}$, mostly because this restriction can be more easily satisfied for averaged datasets. For example, the center second of the Obs-200s data does not need to be in-cloud to have averaged $\mathrm{CWC} \geq 0.01 \mathrm{~g} \mathrm{~m}^{-3}$, while each second of Obs-1s data has to be in-cloud to satisfy this criterion. For Obs-1s data, cloud fraction is calculated for -5 to $+4 \mathrm{~s}$ (a total of $10 \mathrm{~s}$ ) around each second in Table 1 (Figs. 5, 9, 10, 12 and 13).

\begin{tabular}{|c|c|c|c|c|c|c|c|}
\hline \multirow[b]{2}{*}{ Dataset } & \multirow[b]{2}{*}{ Temperature } & \multicolumn{3}{|c|}{$\mathrm{CWC} \geq 0.01 \mathrm{~g} \mathrm{~m}^{-3}$} & \multicolumn{3}{|c|}{ Cloud fraction $\geq 0.6$} \\
\hline & & Liquid & Mixed & Ice & Liquid & Mixed & Ice \\
\hline \multirow[t]{4}{*}{ Obs-1s } & $-10^{\circ} \leq T<0^{\circ} \mathrm{C}$ & $3114(34 \%)$ & $1530(17 \%)$ & $4414(49 \%)$ & $4245(41 \%)$ & $1602(16 \%)$ & $4465(43 \%)$ \\
\hline & $-20^{\circ} \leq T<-10^{\circ} \mathrm{C}$ & $620(18 \%)$ & $176(5 \%)$ & $2687(77 \%)$ & $838(23 \%)$ & $182(5 \%)$ & $2629(72 \%)$ \\
\hline & $-30^{\circ} \leq T<-20^{\circ} \mathrm{C}$ & $210(6 \%)$ & $114(3 \%)$ & $3406(91 \%)$ & $426(10 \%)$ & $117(3 \%)$ & $3672(87 \%)$ \\
\hline & $-40^{\circ} \leq T<-30^{\circ} \mathrm{C}$ & $62(3 \%)$ & $81(4 \%)$ & $1663(92 \%)$ & $76(3 \%)$ & $82(3 \%)$ & $2209(93 \%)$ \\
\hline \multirow[t]{4}{*}{ Obs-10s } & $-10^{\circ} \leq T<0^{\circ} \mathrm{C}$ & $2928(28 \%)$ & $2249(21 \%)$ & $5401(51 \%)$ & $3237(31 \%)$ & $2524(24 \%)$ & $4780(45 \%)$ \\
\hline & $-20^{\circ} \leq T<-10^{\circ} \mathrm{C}$ & $634(16 \%)$ & $276(7 \%)$ & $3108(77 \%)$ & $659(18 \%)$ & $362(10 \%)$ & $2722(73 \%)$ \\
\hline & $-30^{\circ} \leq T<-20^{\circ} \mathrm{C}$ & $180(5 \%)$ & $171(4 \%)$ & 3607 (91\%) & $233(5 \%)$ & $288(7 \%)$ & $3738(88 \%)$ \\
\hline & $-40^{\circ} \leq T<-30^{\circ} \mathrm{C}$ & $28(2 \%)$ & $133(7 \%)$ & $1647(91 \%)$ & $38(2 \%)$ & $154(7 \%)$ & $2152(92 \%)$ \\
\hline \multirow[t]{4}{*}{ Obs-100s } & $-10^{\circ} \leq T<0^{\circ} \mathrm{C}$ & $4332(30 \%)$ & $4492(31 \%)$ & $5772(40 \%)$ & $1057(12 \%)$ & $3722(41 \%)$ & $4228(47 \%)$ \\
\hline & $-20^{\circ} \leq T<-10^{\circ} \mathrm{C}$ & $881(17 \%)$ & $850(16 \%)$ & $3454(67 \%)$ & $70(2 \%)$ & $262(9 \%)$ & $2507(88 \%)$ \\
\hline & $-30^{\circ} \leq T<-20^{\circ} \mathrm{C}$ & $223(5 \%)$ & $204(4 \%)$ & $4261(91 \%)$ & $133(3 \%)$ & $115(3 \%)$ & $3708(94 \%)$ \\
\hline & $-40^{\circ} \leq T<-30^{\circ} \mathrm{C}$ & $0(0 \%)$ & $205(9 \%)$ & 2007 (91\%) & $0(0 \%)$ & $142(7 \%)$ & $1760(93 \%)$ \\
\hline \multirow[t]{4}{*}{ Obs-200s } & $-10^{\circ} \leq T<0^{\circ} \mathrm{C}$ & $4653(27 \%)$ & $6186(37 \%)$ & $6098(36 \%)$ & $434(5 \%)$ & $3913(47 \%)$ & $4013(48 \%)$ \\
\hline & $-20^{\circ} \leq T<-10^{\circ} \mathrm{C}$ & $969(16 \%)$ & $985(17 \%)$ & $3966(67 \%)$ & $0(0 \%)$ & $57(2 \%)$ & $2721(98 \%)$ \\
\hline & $-30^{\circ} \leq T<-20^{\circ} \mathrm{C}$ & $250(5 \%)$ & $258(5 \%)$ & $4738(90 \%)$ & $10(0 \%)$ & $177(5 \%)$ & $3631(95 \%)$ \\
\hline & $-40^{\circ} \leq T<-30^{\circ} \mathrm{C}$ & $0(0 \%)$ & $262(10 \%)$ & $2261(90 \%)$ & $0(0 \%)$ & $26(2 \%)$ & 1707 (98\%) \\
\hline \multirow[t]{4}{*}{ CAM-collocated } & $-10^{\circ} \leq T<0^{\circ} \mathrm{C}$ & $6599(60 \%)$ & $289(3 \%)$ & $4028(37 \%)$ & $4042(59 \%)$ & $173(3 \%)$ & $2689(39 \%)$ \\
\hline & $-20^{\circ} \leq T<-10^{\circ} \mathrm{C}$ & $705(53 \%)$ & $18(1 \%)$ & $604(46 \%)$ & $700(18 \%)$ & $205(5 \%)$ & 2995 (77\%) \\
\hline & $-30^{\circ} \leq T<-20^{\circ} \mathrm{C}$ & $0(0 \%)$ & $0(0 \%)$ & $978(100 \%)$ & $0(0 \%)$ & $0(0 \%)$ & $3315(100 \%)$ \\
\hline & $-40^{\circ} \leq T<-30^{\circ} \mathrm{C}$ & $0(0 \%)$ & $0(0 \%)$ & $292(100 \%)$ & $0(0 \%)$ & $0(0 \%)$ & $2890(100 \%)$ \\
\hline \multirow[t]{4}{*}{ CAM-domain } & $-10^{\circ} \leq T<0^{\circ} \mathrm{C}$ & $112293(70 \%)$ & $6735(4 \%)$ & $40321(25 \%)$ & $84882(63 \%)$ & $4802(4 \%)$ & $45661(34 \%)$ \\
\hline & $-20^{\circ} \leq T<-10^{\circ} \mathrm{C}$ & $5404(29 \%)$ & $195(1 \%)$ & $12793(70 \%)$ & $5564(6 \%)$ & $1236(1 \%)$ & $92236(93 \%)$ \\
\hline & $-30^{\circ} \leq T<-20^{\circ} \mathrm{C}$ & $66(1 \%)$ & $3(<1 \%)$ & $12459(99 \%)$ & $28(<1 \%)$ & $32(<1 \%)$ & $72318(100 \%)$ \\
\hline & $-40^{\circ} \leq T<-30^{\circ} \mathrm{C}$ & $0(0 \%)$ & $0(0 \%)$ & $10558(100 \%)$ & $0(0 \%)$ & $0(0 \%)$ & $54960(100 \%)$ \\
\hline
\end{tabular}

from observations in the high northern latitudes $\left(42^{\circ}-76^{\circ} \mathrm{N}\right)$, respectively (Korolev et al. 2017, 2003). At $-30^{\circ}$ to $-10^{\circ} \mathrm{C}, 1-\mathrm{Hz}$ observations from the ORCAS campaign show lower mixed-phase frequencies $(3 \%-5 \%)$ than those in previous studies of Arctic clouds (13\%-17\%) (Korolev et al. 2017, 2003) (Table S4).

Figure 6 shows the observed geometric means of LWC, IWC, $\mathrm{Nc}_{\text {liq }}$, and $\mathrm{Nc}_{\text {ice }}$ at $5^{\circ} \mathrm{C}$ intervals from $-40^{\circ}$ to $0^{\circ} \mathrm{C}$ for respective cloud phases. For liquid and mixed phases, Obs-1s data show larger averaged quantities by one to two orders of magnitude compared with the coarser-resolution data, since the spatial-averaged segments may include both in-cloud and clear-sky conditions. For ice phase, Obs-200s data show larger IWC and $\mathrm{Nc}_{\text {ice }}$ than Obs-1s data, likely due to the restriction of no more than $10 \%$ of missing values in the spatial averaging, which only allows relatively long, continuous in-cloud segments that are often associated with higher IWC and $\mathrm{Nc}_{\text {ice }}$ to be used in Obs-200s data. Trends in the averaged quantities with respect to temperature are generally similar among various scales of observations, except for one temperature bin of $-30^{\circ}$ to $-25^{\circ} \mathrm{C}$ in mixed phase likely due to the smaller sample sizes (Fig. S7). For Obs-1s data, LWC and IWC generally decrease with decreasing temperature for all cloud phases. For Obs-200s data, the average IWC and $\mathrm{Nc}_{\text {ice }}$ are one to two orders of magnitude higher in ice phase compared with mixed phase, whereas the average LWC and $\mathrm{Nc}_{\text {liq }}$ are 3-10 times higher in mixed phase than liquid phase at $-10^{\circ}$ to $0^{\circ} \mathrm{C}$ but more similar at other temperatures. For both liquid and mixed phases, average $\mathrm{Nc}_{\text {liq }}$ slightly increases with decreasing temperature at $-25^{\circ}$ to $0^{\circ} \mathrm{C}$, and it decreases with decreasing temperature below $-25^{\circ} \mathrm{C}$. In comparison, the trends in average $\mathrm{Nc}_{\text {ice }}$ vary between mixed and ice phases. In mixed phase, average $\mathrm{Nc}_{\text {ice }}$ decreases (increases) with decreasing temperature above (below) $-25^{\circ} \mathrm{C}$, whereas in ice phase average $\mathrm{Nc}_{\text {ice }}$ increases with decreasing temperature.

Figure 7 further compares the geometric means of IWC, $\mathrm{LWC}, \mathrm{Nc}_{\text {liq }}$, and $\mathrm{Nc}_{\text {ice }}$ between simulations and the Obs-200s data. For liquid phase, simulated average LWC values (i.e., $0.01-0.1 \mathrm{~g} \mathrm{~m}^{-3}$ ) are about one order of magnitude greater than the Obs-200s data, and are more comparable to those in Obs- $1 \mathrm{~s}$. The average $\mathrm{Nc}_{\text {liq }}$ in liquid phase in CAM-domain data is about 3 times that 

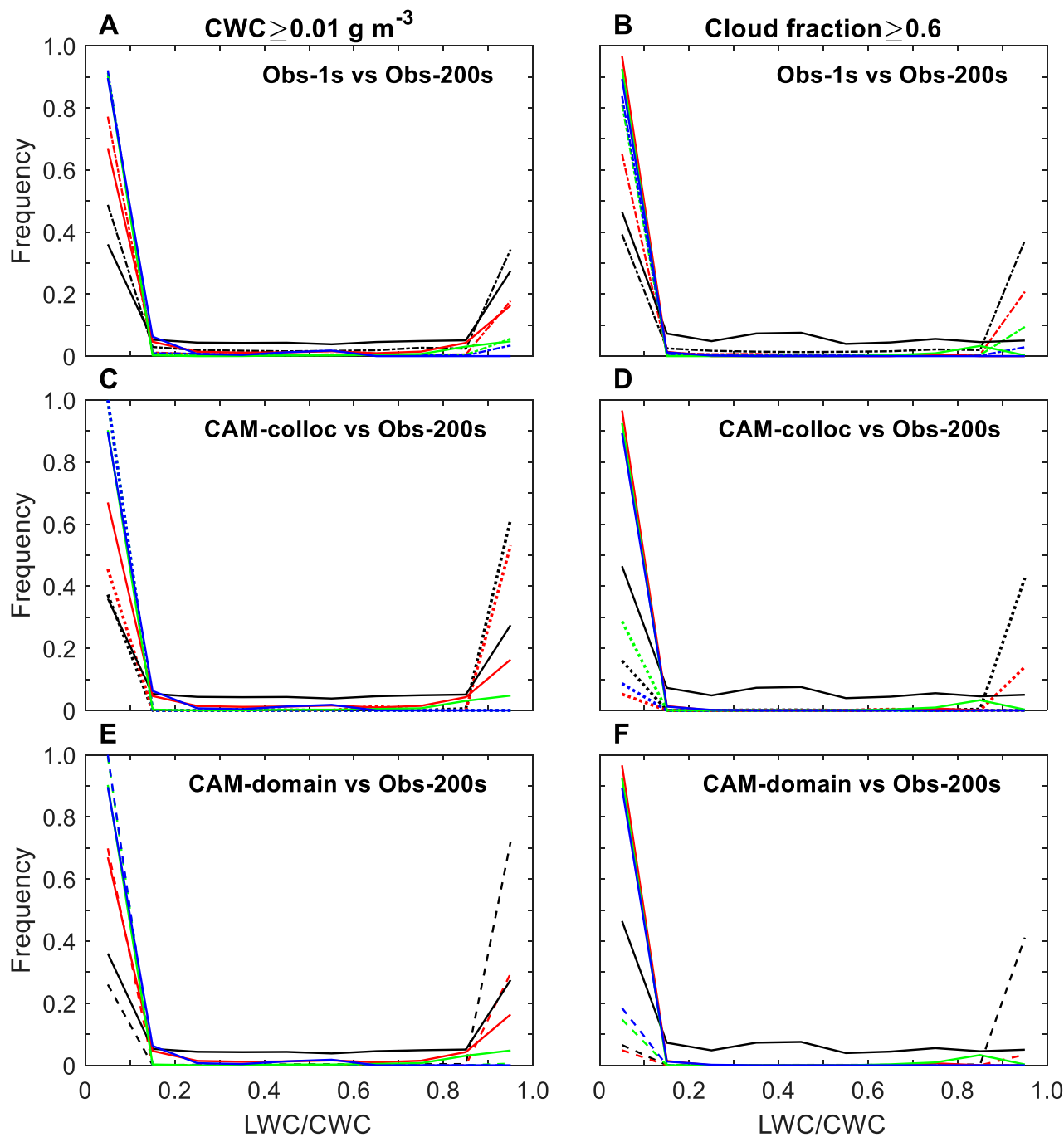

\begin{tabular}{|c|c|c|c|c|c|c|}
\hline $\begin{array}{r}\text { Obs-1s: } \\
\text { Obs-200s: } \\
\text { CAM-colloc: } \\
\text { CAM-domain: }\end{array}$ & $\begin{aligned}-10^{\circ} & \leq \mathrm{T}<0^{\circ} \mathrm{C} \\
- & -10^{\circ} \leq \mathrm{T}<0^{\circ} \mathrm{C} \\
-10^{\circ} & \leq \mathrm{T}<0^{\circ} \mathrm{C} \\
--1 & -10^{\circ} \leq \mathrm{T}<0^{\circ} \mathrm{C}\end{aligned}$ & $\begin{aligned}-20^{\circ} & \leq \mathrm{T}<-10^{\circ} \mathrm{C} \\
-20^{\circ} & \leq \mathrm{T}<-10^{\circ} \mathrm{C} \\
-20^{\circ} & \leq \mathrm{T}<-10^{\circ} \mathrm{C} \\
- & -20^{\circ} \leq \mathrm{T}<-10^{\circ} \mathrm{C}\end{aligned}$ & $\bar{Z}$ & $\begin{array}{l}-30^{\circ} \leq \mathrm{T}<-20^{\circ} \mathrm{C} \\
-30^{\circ} \leq \mathrm{T}<-20^{\circ} \mathrm{C} \\
-30^{\circ} \leq \mathrm{T}<-20^{\circ} \mathrm{C} \\
-30^{\circ} \leq \mathrm{T}<-20^{\circ} \mathrm{C}\end{array}$ & $\overline{-}$ & $\begin{array}{l}-40^{\circ} \leq \mathrm{T}<-30^{\circ} \mathrm{C} \\
-40^{\circ} \leq \mathrm{T}<-30^{\circ} \mathrm{C} \\
-40^{\circ} \leq \mathrm{T}<-30^{\circ} \mathrm{C} \\
-40^{\circ} \leq \mathrm{T}<-30^{\circ} \mathrm{C}\end{array}$ \\
\hline
\end{tabular}

FIG. 5. Occurrence frequencies of LWC/CWC ratios compared between Obs-200s (solid line in all panels) and other data, namely (a),(b) Obs-1s, (c),(d) CAM-collocated, and (e),(f) CAM-domain. Two in-cloud thresholds are used: (left) $C W C \geq 0.01 \mathrm{~g} \mathrm{~m}^{-3}$ and (right) cloud fraction $\geq 0.6$. Obs- $1 \mathrm{~s}$ data calculate cloud fraction in 10 -s intervals $( \pm 5 \mathrm{~s})$. The number of samples of liquid, mixed, and ice phases are shown in Table 1. Figure S6 and Table S4 show results using $5^{\circ} \mathrm{C}$ bins.

in the observations from $-20^{\circ}$ to $0^{\circ} \mathrm{C}$. Previously, shallow convective detrainment was found to be the main source of cloud liquid over the Southern Ocean (Kay et al. 2016a). Since the parameterization of shallow convective detrainment defines cloud ice mass fraction to be larger than 0.1 below $-8^{\circ} \mathrm{C}$, many fewer liquid phase samples (i.e., ice mass fraction $<0.1$ ) can exist below $-8^{\circ} \mathrm{C}$ in the simulations (Fig. S8). Therefore, these liquid phase samples are more likely contributed by shallow convection detrainment above $-8^{\circ} \mathrm{C}$ and by other moist physical processes (e.g., microphysics "MPDLIQ" and macrophysics "MACPDLIQ") below $-8^{\circ} \mathrm{C}$.

For mixed phase, the simulations consistently show lower LWC, IWC, and $\mathrm{Nc}_{\text {liq }}$ than the Obs-200s data at $-25^{\circ}$ to $0^{\circ} \mathrm{C}$ by a factor of $3-10$, while the simulated $\mathrm{Nc}_{\text {ice }}$ is much higher than the observations at $-25^{\circ}$ to $-5^{\circ} \mathrm{C}$ by a factor of $3-500$. The overestimation of $\mathrm{Nc}_{\text {ice }}$ in simulations is consistent with previous findings of the parameterization of Meyers et al. (1992) overestimating ice number concentrations (e.g., Liu 


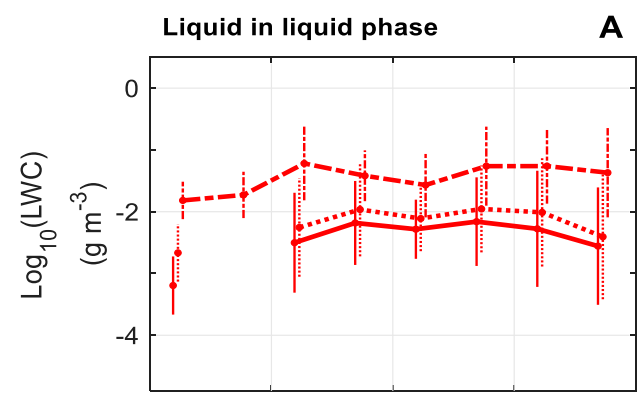

A
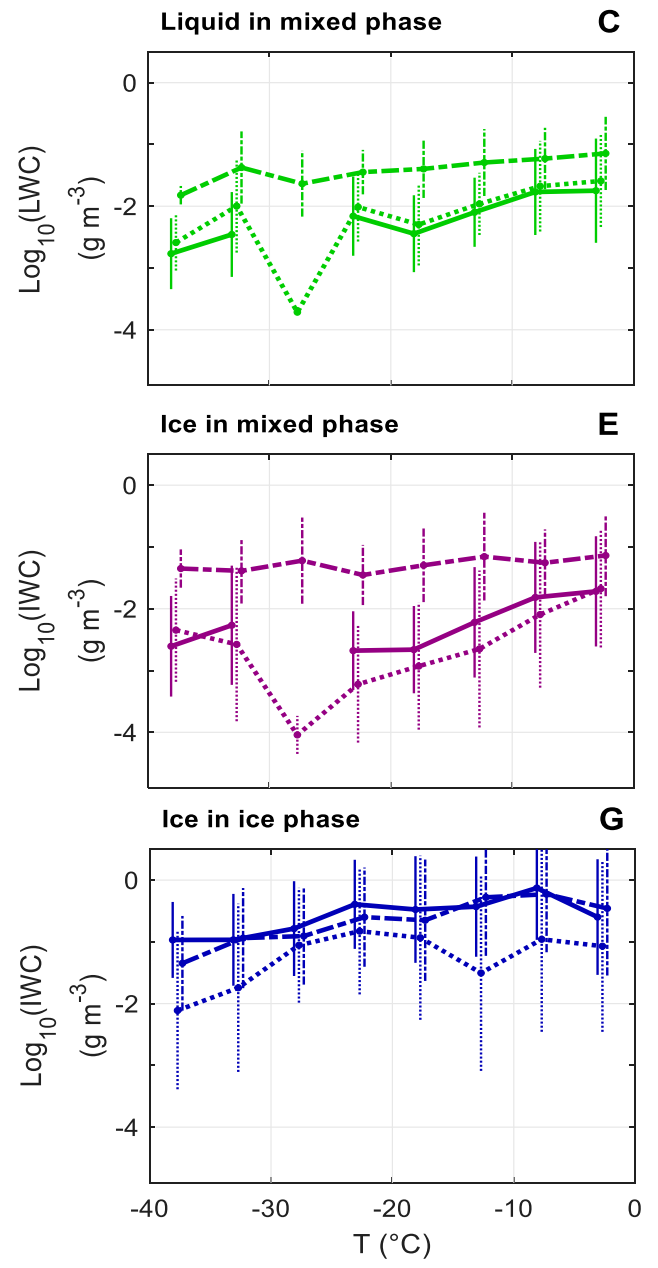

B

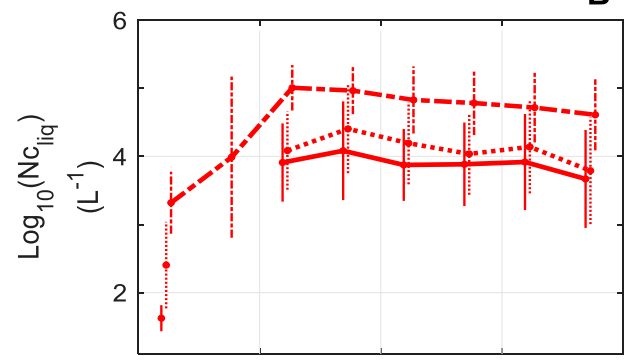

D
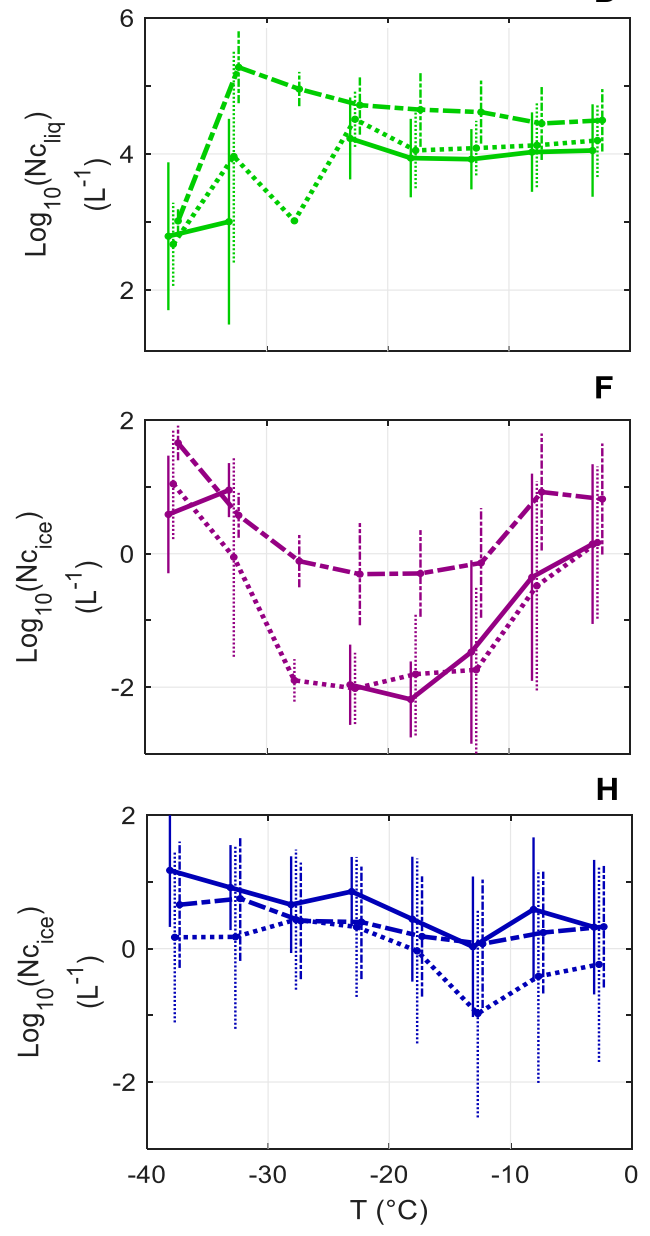

\begin{tabular}{|c|c|c|c|c|}
\hline $\begin{array}{l}\text { Obs-1s: } \\
\text { Obs-100s: } \\
\text { Obs-200s: }\end{array}$ & 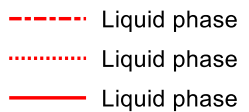 & $\begin{array}{r}\text { Liquid in mixed phase } \\
\text { Liquid in mixed phase } \\
\end{array}$ & $\begin{array}{r}\text { Ice in mixed phase } \\
\text {............ Ice in mixed phase } \\
\text { Ice in mixed phase }\end{array}$ & $\begin{array}{r}\text { Ice phase } \\
\text {............ Ice phase } \\
\end{array}$ \\
\hline
\end{tabular}

FIG. 6. Geometric means of (a),(c) LWC, (e),(g) IWC, (b),(d) $\mathrm{Nc}_{\text {liq }}$, and (f),(h) $\mathrm{Nc}_{\text {ice }}$ for three cloud phases at $5^{\circ} \mathrm{C}$ intervals between $-40^{\circ}$ and $0^{\circ} \mathrm{C}$ for various scales of observations. Whiskers in Figs. 6-8 represent plus and minus one standard deviation, and the number of samples are shown in Figs. S7-S9. Besides the restriction of no more than $10 \%$ of the averaged segments reporting missing values, the analysis is restricted to observational data with at least $1 \mathrm{~s}$ of CWC $>$ $0.001 \mathrm{~g} \mathrm{~m}^{-3}$ and at least $1 \mathrm{~s}$ of either $\mathrm{Nc}_{\text {liq }}>100 \mathrm{~L}^{-1}$ or $\mathrm{Nc}_{\text {ice }}>0.01 \mathrm{~L}^{-1}$.

et al. 2011; DeMott et al. 2010). Another main difference is seen for ice phase, where simulated IWC is about two orders of magnitude lower than Obs-200s data, suggesting that the simulated ice particles are unrealistically smaller than the observations at $-40^{\circ}$ to $-10^{\circ} \mathrm{C}$ since the $\mathrm{Nc}_{\text {ice }}$ values are similar at this temperature range. Note that averaged IWC in ice phase is 10 times higher in Obs-200s than in Obs-1s 
Liquid in liquid phase

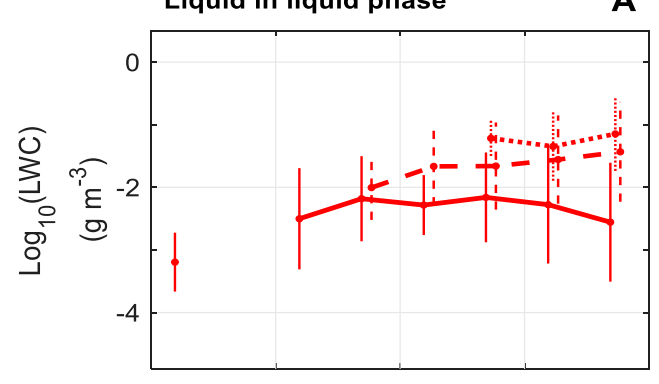

Liquid in mixed phase
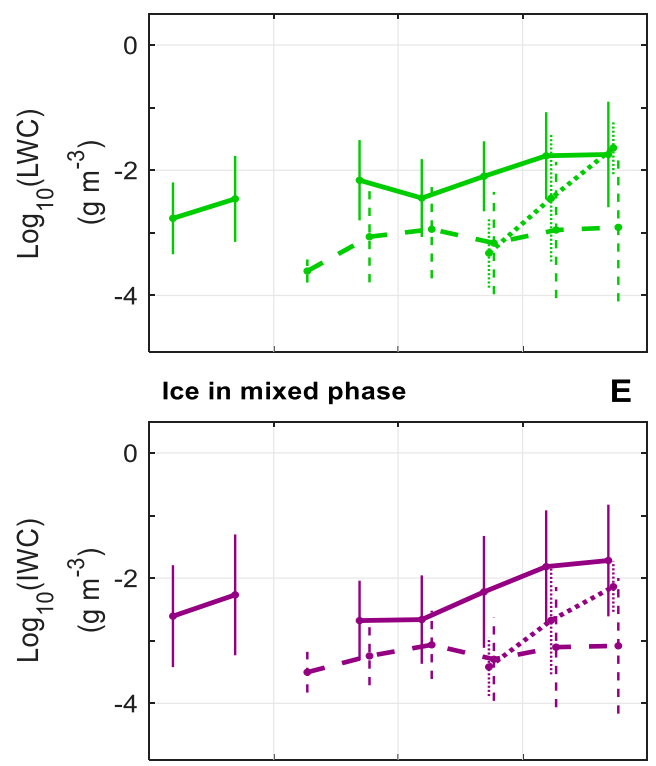

Ice in ice phase

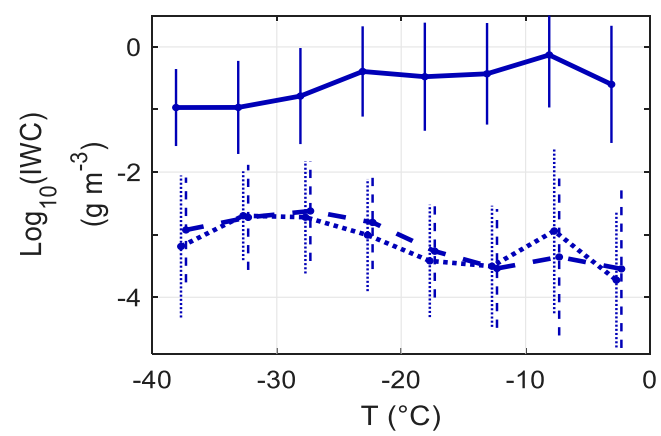

A

C
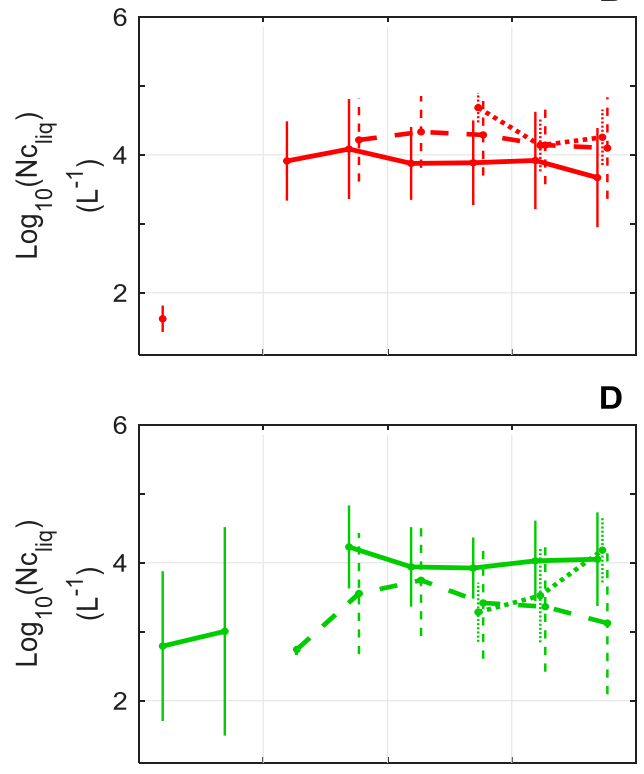

$\mathbf{F}$
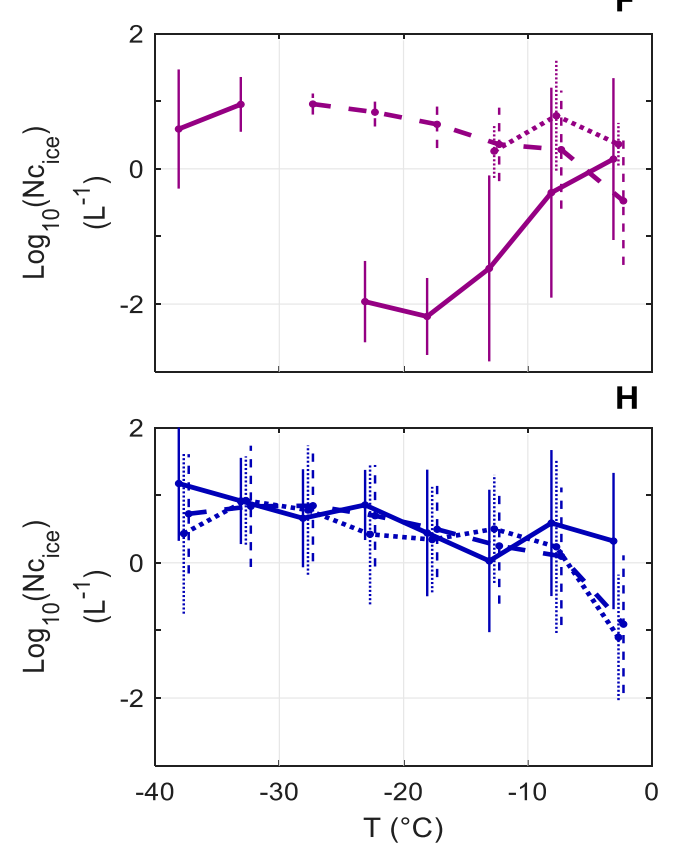

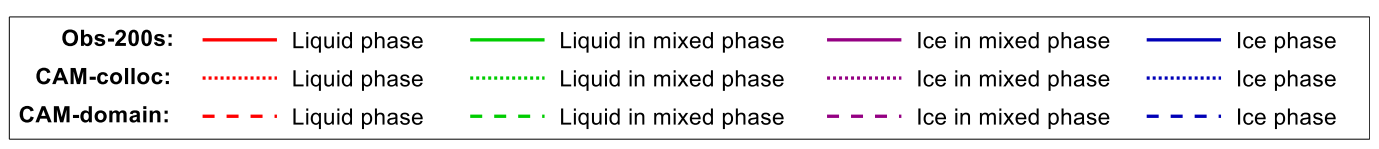

FIG. 7. As in Fig. 6, but for Obs-200s, CAM-collocated, and CAM-domain datasets. In addition to the restriction of Obs-200s data as mentioned in the Fig. 6 caption, simulation output is restricted to those with both "CLDICE" and "CLDLIQ" $\geq 4.68 \times 10^{-5} \mathrm{~g} \mathrm{~m}^{-3}$. These restrictions help to filter out very low values of IWC, $\mathrm{LWC}, \mathrm{Nc}_{\text {liq }}$, and $\mathrm{Nc}_{\text {ice. }}$. Particularly, restrictions on simulated CLDICE and CLDLIQ are used since filtering out low IWC and LWC alone does not exclude all of the low number concentrations reported in NUMICE and NUMLIQ. 

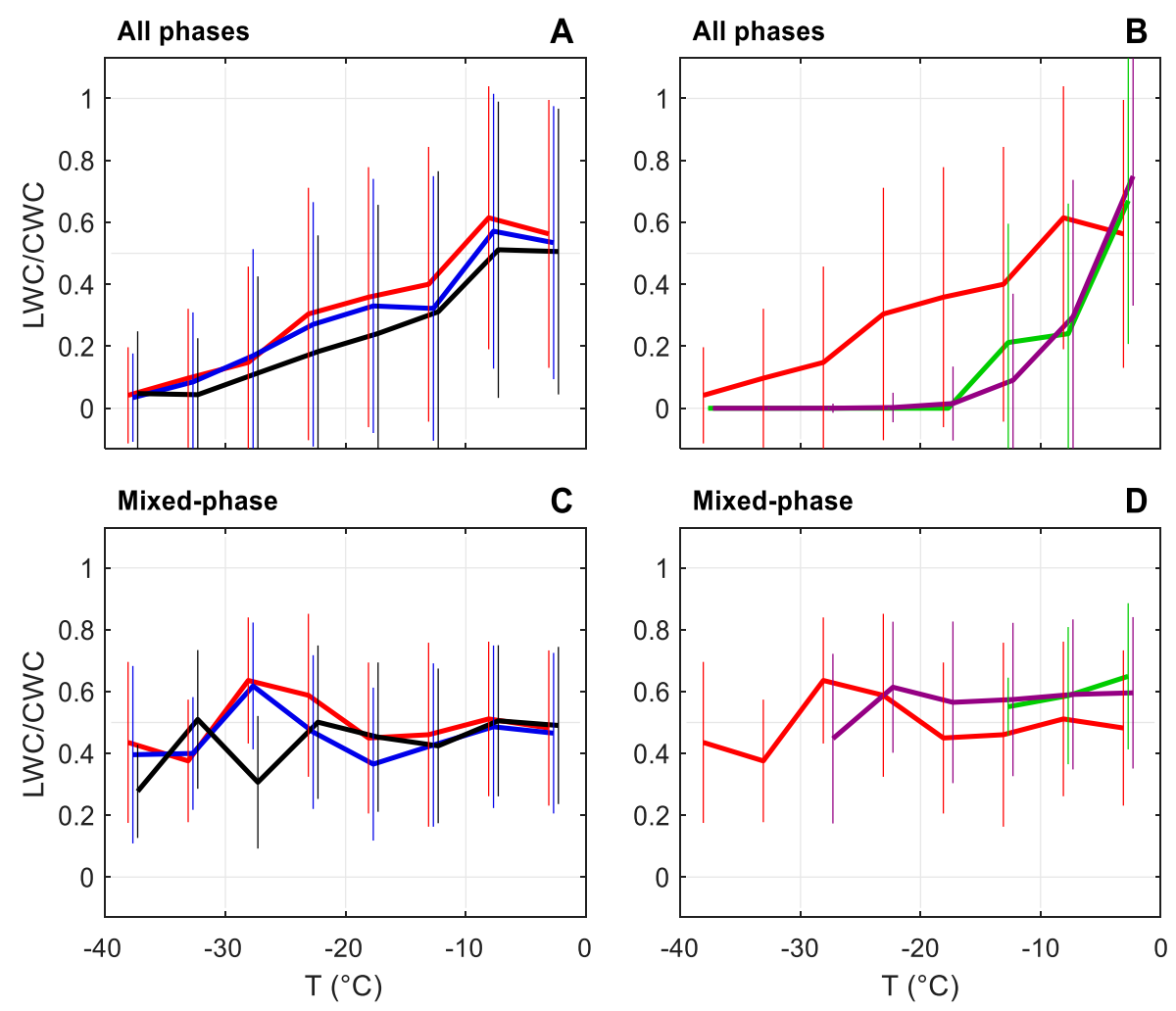

Obs-1s: — Obs-100s: —obs-200s:

CAM-colloc:

CAM-domain:

FIG. 8. Average LWC/CWC ratio for (a),(b) total in-cloud conditions and (c),(d) mixed phase only: (left) Obs-1s, Obs-100s, and Obs-200s and (right) Obs-200s, CAM-collocated, and CAM-domain.

data, while averaged $\mathrm{LWC}, \mathrm{Nc}_{\text {liq }}$, and $\mathrm{Nc}_{\text {ice }}$ are 10 times lower in Obs-200s data. Thus, if IWC in ice phase were to follow a similar decreasing trend with coarser scales, the difference between CAM5 and Obs-200s would have been much smaller. In contrast with ice-phase IWC, ice-phase $\mathrm{Nc}_{\text {ice }}$ in the simulations is lower than observations by a factor of 5-30 from $-10^{\circ}$ to $0^{\circ} \mathrm{C}$, respectively, possibly due to insufficient secondary ice production and/or missing marine organic aerosols as ice nucleating particles (INPs) in the simulations, which can be important at that temperature range over the Southern Ocean. These findings of ice phase are unlikely affected by the sampling volume, since all the datasets have a sufficient number of ice-phase samples (Fig. S8).

The statistical robustness of the comparisons is supported by the fact that all of the average quantities in Fig. 7 show very similar results between CAMcollocated and CAM-domain data, which almost never differ by more than one order of magnitude for the same temperature bins. In addition, sensitivity tests show maximum differences of $33 \%$ (29\%) and $57 \%$ $(32 \%)$ in mass (number) concentrations of cloud liquid and cloud ice, respectively, due to different ranges of particle size distributions in observations and simulations (Table S3), which proves that the differences in the observed and simulated quantities by more than one order of magnitude cannot be all attributed to size range differences.

Average mass ratios of $\mathrm{LWC} / \mathrm{CWC}$ are shown at various temperatures for two categories: total incloud conditions and mixed phase only (Fig. 8), and the numbers of samples are shown in Fig. S9. Compared with average LWC and IWC, the observed ratios of LWC/CWC only slightly increase with spatial averaging, because the mass ratios have cancelled out the effect of including more clear-sky conditions on larger averaging scales. Compared with Obs-200s data for total in-cloud conditions, simulations show lower (higher) LWC/CWC ratios by $0.1-0.3(0.2)$ at $-40^{\circ}$ to $-5^{\circ} \mathrm{C}\left(-5^{\circ}\right.$ to $\left.0^{\circ} \mathrm{C}\right)$, due to the combined effects from overestimated LWC in liquid phase, underestimated LWC in mixed phase, and underestimated IWC in both ice and mixed phases in simulations (Fig. 7). The underestimated LWC/CWC ratios for total in-cloud conditions in the simulations is 


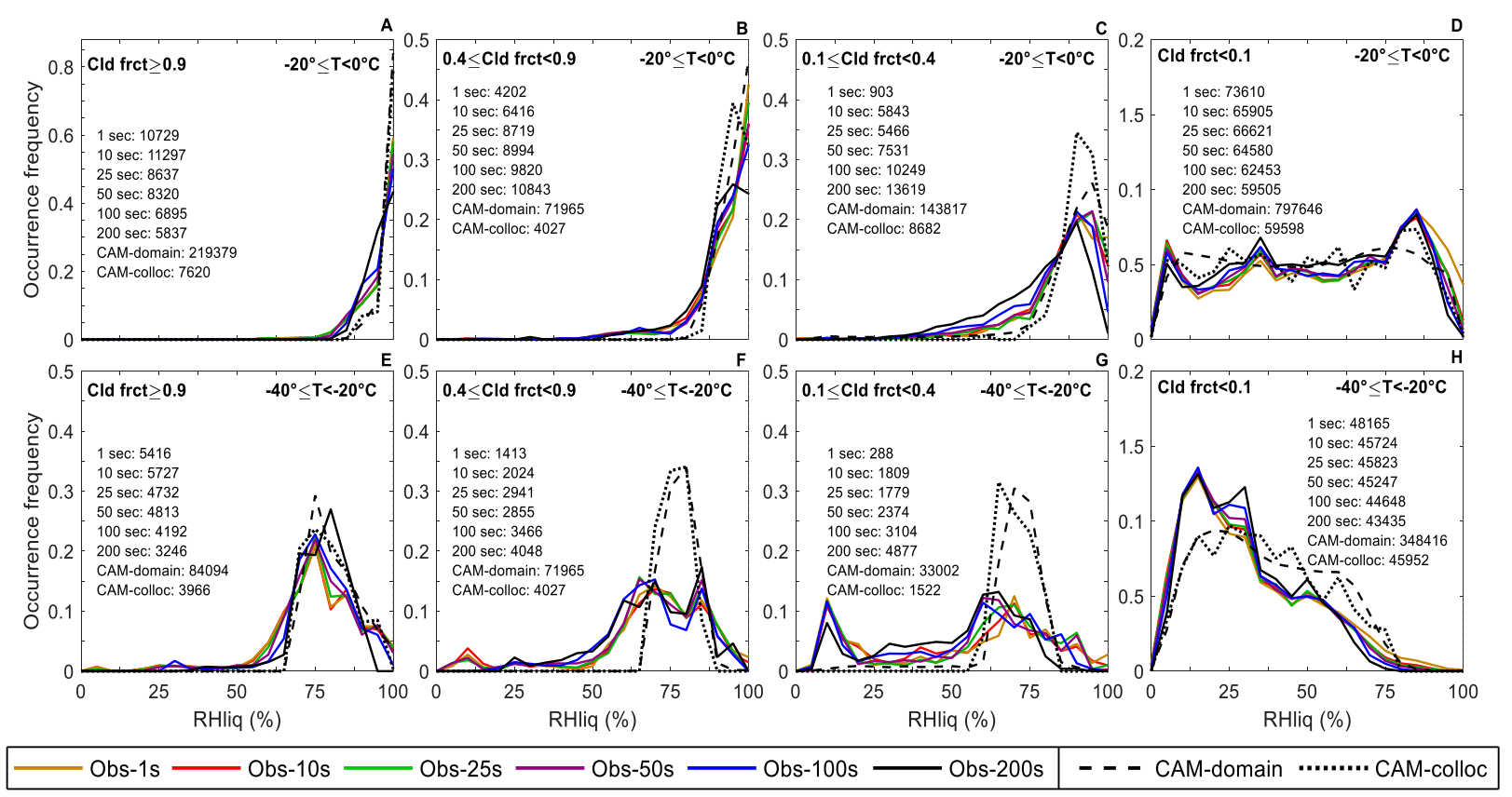

FIG. 9. RHliq PDFs for various temperatures and cloud fractions: (a)-(d) $-20^{\circ}$ to $0^{\circ} \mathrm{C}$ and (e)-(h) $-40^{\circ}$ to $-20^{\circ} \mathrm{C}$. Various scales of observations (colored solid lines), CAM-collocated (dotted), and CAM-domain (dashed) data are shown. Results are binned in $5 \%$ intervals of RHliq, except for $<2.5 \%$. The number of samples generally increases with increasing averaging scales when using less strict cloud fraction restrictions (i.e., cloud fraction $<0.9$ ), since it is more likely for samples at larger scales to be partially in-cloud than samples at smaller scales.

consistent with the previous comparisons between CAM5 simulations and the GCM-oriented CALIPSO cloud product (Cesana and Chepfer 2013). On the other hand, the simulations show slightly higher LWC/ CWC for mixed phase compared with observations at $-20^{\circ}$ to $0^{\circ} \mathrm{C}$. The differences between total in-cloud and mixed phase only conditions suggest that phase partitioning parameterizations may need to be specified for different phases.

\section{c. Relative humidity distributions in relation to temperature and cloud fraction}

$\mathrm{RH}$ distributions have large influences on the evolution of cloud condensates. Thus, it is important to examine RH distributions in conjunction with cloud microphysical and macrophysical properties. In particular, CAM5 calculates ice cloud fraction as a function of RHi (Gettelman et al. 2010), highlighting the need for validating the RH distributions at various cloud fractions. Probability density functions (PDFs) of RHliq (Fig. 9) and RHi (Fig. 10) are shown for all cloud phases at various cloud fractions. As temperature decreases from the range of $-20^{\circ}$ to $0^{\circ} \mathrm{C}$ to the range of $-40^{\circ}$ to $-20^{\circ} \mathrm{C}$, the peak position of RHliq distribution shifts from around liquid saturation to lower values, in addition to a broadening effect on the distributions. As cloud fraction decreases from $>0.9$ to $<0.1$, the peak position of RHliq decreases from $100 \%$ to $\sim 85 \%$ at $-20^{\circ}$ to $0^{\circ} \mathrm{C}$, and from $\sim 75 \%$ to $15 \%$ at $-40^{\circ}$ to $-20^{\circ} \mathrm{C}$, respectively.

The simulations agree well with the observations for RHliq between $-20^{\circ}$ and $0^{\circ} \mathrm{C}$. However, the simulations show higher frequencies of RHi between $105 \%$ and $115 \%$ than Obs-200s data for cloud fraction $>0.9$ at all temperature ranges. In addition, the simulations show narrower RHliq and RHi distributions compared with observations at cloud fractions of 0.1-0.9, lacking the large variabilities of RHliq distributions as seen in the observations. When restricting cloud fractions, the spatial averaging has minimal impacts on RH PDFs, and the two sets of simulations agree well with each other, which further demonstrates the robustness of such comparisons on RH PDFs using datasets with different sample volumes.

A layer-normalized frequency distribution of RHi at various temperatures and cloud fractions is shown for the Obs-200s and CAM-domain datasets (Fig. 11). The RHi frequency is calculated as the number of samples in each $1^{\circ} \mathrm{C} \times 5 \%$ bin divided by the total number of samples in each $1^{\circ} \mathrm{C}$ interval. Previously, layer-normalized RHi frequency was analyzed for $-88^{\circ}$ to $-23^{\circ} \mathrm{C}$ based on in situ observations from $68^{\circ} \mathrm{N}$ to $21^{\circ} \mathrm{S}$ in the UT/LS (Krämer et al. 2009). Here we extend that previous work to $-67^{\circ}$ to $0^{\circ} \mathrm{C}$ at higher 

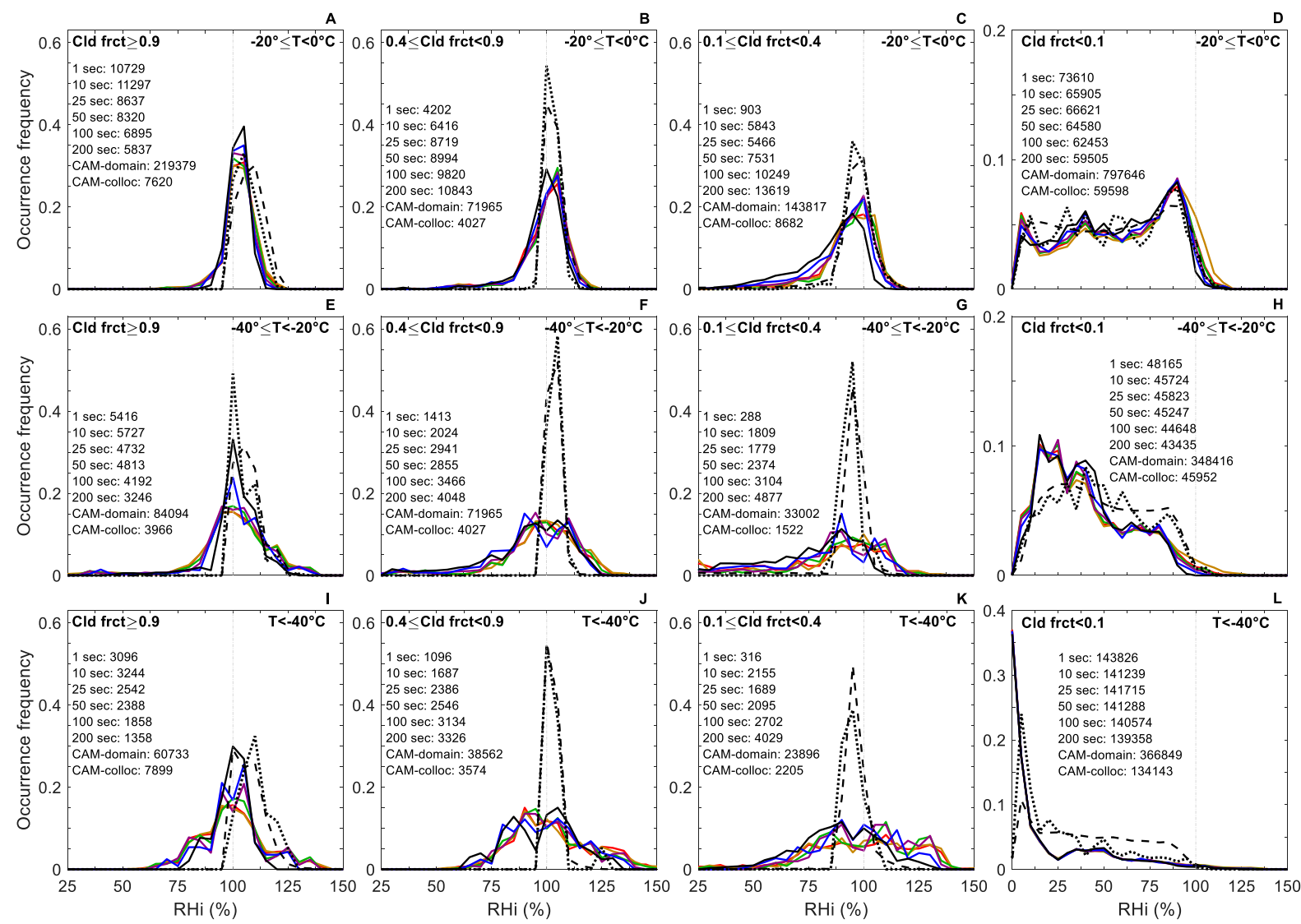

Obs-1s Obs-10s

Obs-25s Obs-50s

Obs-100s

Obs-200s

- - - CAM-domain $\ldots . . . .$. CAM-colloc

FIG. 10. As in Fig. 9, but for RHi and also including (i)-(1) $T<-40^{\circ} \mathrm{C}$.

southern latitudes. The differences of normalized RHi frequency between the simulations and observations are also shown (Figs. 11g-i). For cloud fraction $\geq 0.9$, Obs-200s data show the maximum RHi at $125 \%$. CAM-domain data show higher maximum RHi but only for very few cases (Fig. S10). For cloud fractions of 0.1-0.9, the simulations underestimate the frequencies of $\mathrm{RHi}<90 \%$ and $\mathrm{RHi}>110 \%$ compared with the observations. This further illustrates that the smaller variabilities of RH PDFs in the simulations (as seen in Figs. 9 and 10) are consistently shown at all the temperatures from $-67^{\circ}$ to $0^{\circ} \mathrm{C}$. At low cloud fraction $(<0.1)$, the simulations underestimate the frequencies of relatively dry conditions from $-60^{\circ}$ to $-50^{\circ} \mathrm{C}$ and underestimate the frequencies of moist conditions (near ice saturation) from $-8^{\circ}$ to $0^{\circ} \mathrm{C}$.

\section{d. RH distributions for liquid, mixed, and ice phase conditions}

In this section, we further examine the influences of cloud phases on cumulative frequency distributions
(CFDs) of RHliq and RHi in Figs. 12 and 13, respectively. This analysis is restricted to cloud fraction $\geq 0.9$, and separated by $10^{\circ} \mathrm{C}$ intervals from $-40^{\circ}$ to $0^{\circ} \mathrm{C}$. For observations from $\sim 0.1$ - to $50-\mathrm{km}$ scales, similar CFDs of RHliq are seen for liquid and mixed phases, all of which are close to liquid saturation. For example, 98\%, $90 \%$, and $64 \%$ of the Obs- 10 s mixed-phase data show RHliq $>90 \%$ at $-10^{\circ}$ to $0^{\circ} \mathrm{C},-20^{\circ}$ to $-10^{\circ} \mathrm{C}$, and $-30^{\circ}$ to $-20^{\circ} \mathrm{C}$, respectively. This result is consistent with the theoretical understanding that MPCs generally show RH near liquid saturation at steady-state conditions (Korolev and Mazin 2003). The slight deviation from liquid saturation in liquid and mixed phases is consistent with previously reported inhomogeneities such as cloud holes (Korolev and Isaac 2006). The simulations show nearly identical RHliq CFDs to observations for liquid phase, except for a lack of liquid droplets for colder temperatures at $-40^{\circ}$ to $-30^{\circ} \mathrm{C}$ (Fig. 12d). For mixed phase, the CAM-domain data show remarkable similarities to observations for RHliq CFDs at $-20^{\circ}$ to $0^{\circ} \mathrm{C}$ (note that the CAM-collocated data have very few 

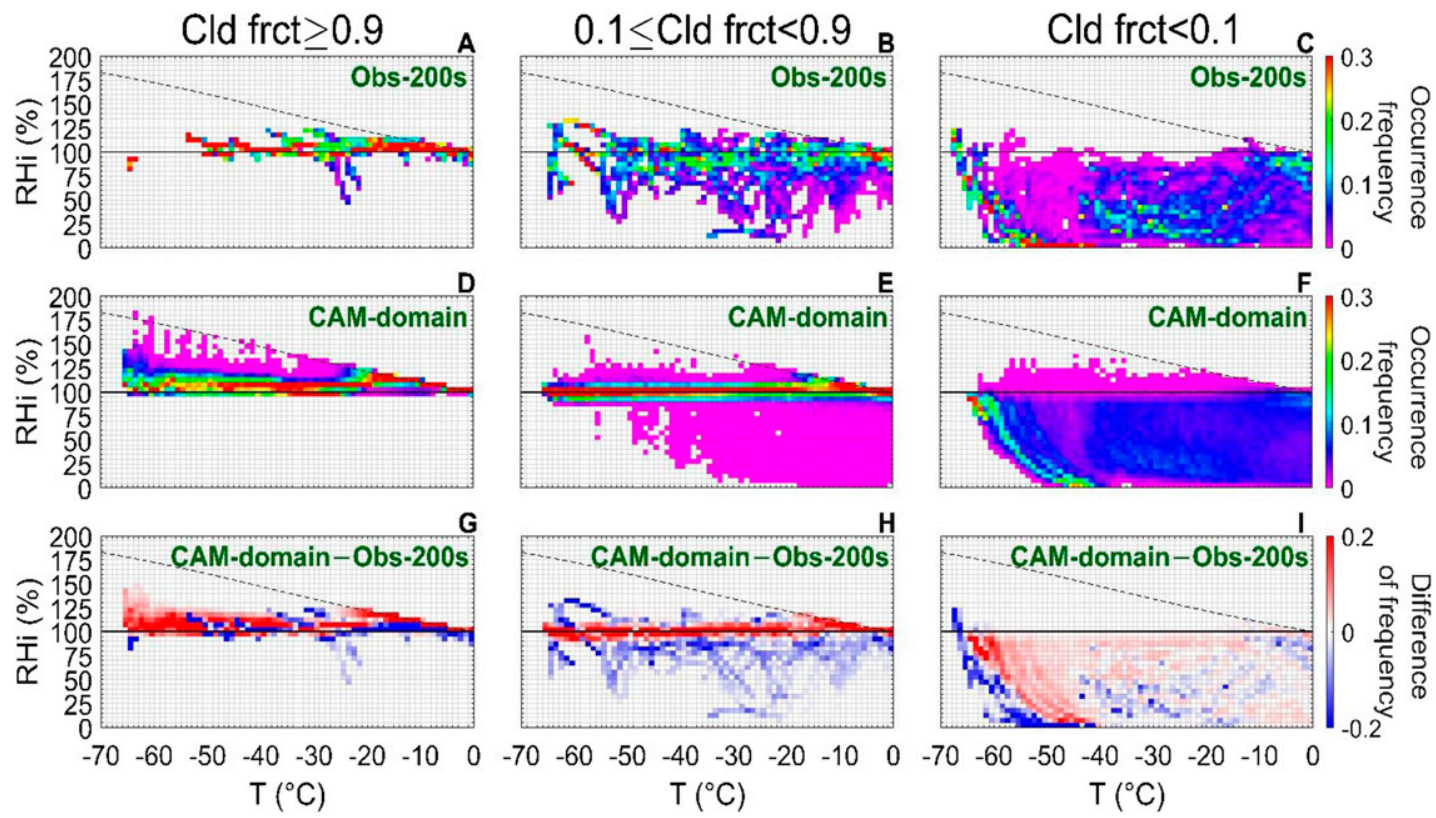

FIG. 11. RHi frequency distributions at various temperatures for (a)-(c) Obs-200s, (d)-(f) CAM-domain, and (g)(i) their differences (CAM-domain - Obs-200s). Frequency in each $1^{\circ} \mathrm{C} \times 5 \%$ bin is normalized by the total number of samples in each $1^{\circ} \mathrm{C}$ interval. Solid and dashed lines show ice and liquid saturation, respectively.

samples at this condition), yet no mixed phase is shown in the simulations below $-30^{\circ} \mathrm{C}$.

The largest differences between the observations and simulations are seen in ice phase, particularly for $-30^{\circ}$ to $0^{\circ} \mathrm{C}$ (Figs. 12i-k), where both simulations underestimate the occurrence frequencies of RHliq $<95 \%$ by a fraction of $0.2-0.4$. In fact, for ice phase, only $80 \%, 59 \%$, and $11 \%$ of the Obs- 10 s ice-phase data show RHliq $>90 \%$ at $-10^{\circ}$ to $0^{\circ} \mathrm{C},-20^{\circ}$ to $-10^{\circ} \mathrm{C}$, and $-30^{\circ}$ to $-20^{\circ} \mathrm{C}$, respectively. These

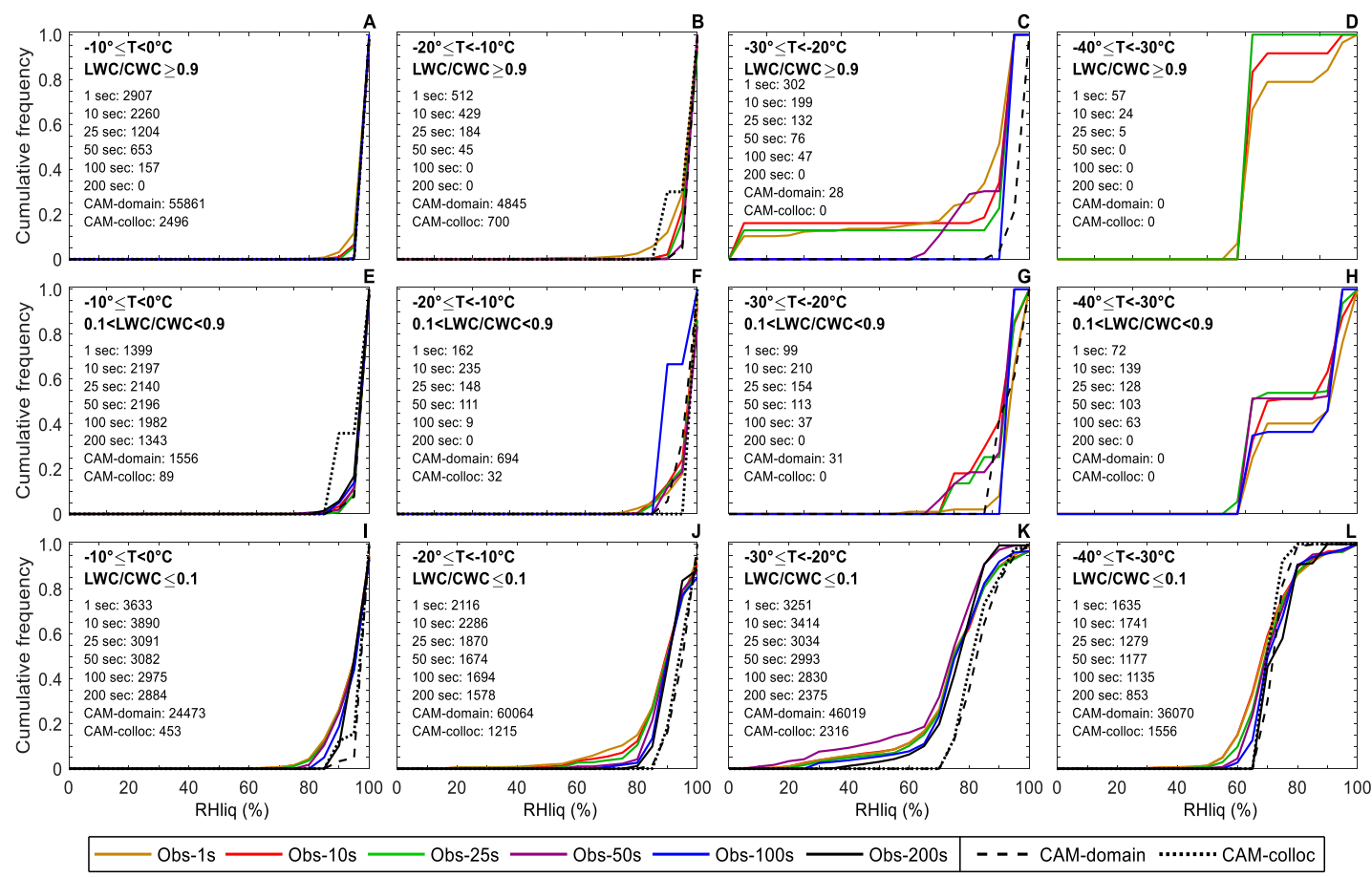

FIG. 12. RHliq CFDs for three cloud phases, restricted to cloud fraction $\geq 0.9$. Results are binned in $5 \%$ intervals of RHliq, except for $<2.5 \%$. 

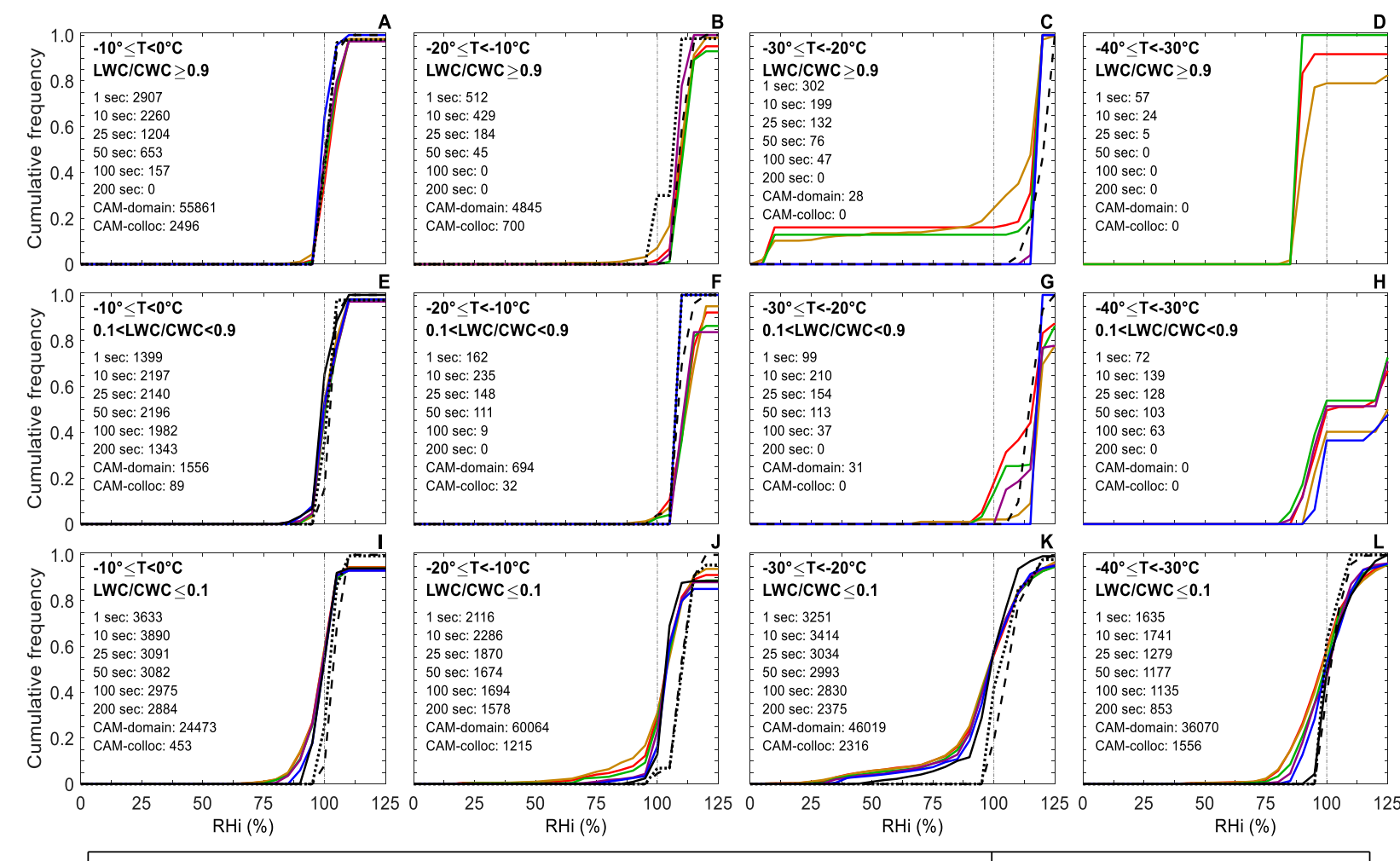

D

- Obs-1s - Obs-10s - Obs-25s - Obs-50s -

Obs-100s - Obs-200s

- - - CAM-domain ......... CAM-colloc

FIG. 13. As in Fig. 12, but for RHi.

results indicate that even though $\mathrm{RH}$ is centered at liquid saturation in liquid and mixed phase as low as $-30^{\circ} \mathrm{C}$ on the scale of $\sim 0.1-50 \mathrm{~km}$ with liquid mass fraction $>0.1$ and cloud fraction $\geq 0.9$, such assumption is not applicable when $\mathrm{LWC} / \mathrm{CWC} \leq 0.1$. A similar deviation from liquid saturation with increasing IWC/CWC ratio was reported previously (Korolev and Isaac 2008), and our results do not show significant impacts from spatial averaging due to the restriction of cloud fraction $\geq 0.9$.

The CFDs of RHi also show large differences between observations and simulations for ice phase (Fig. 13), where simulations overestimate the frequency of ISS conditions at $-30^{\circ}$ to $0^{\circ} \mathrm{C}$. Such discrepancy is possibly due to the assumption used in the ice microphysics parameterization in CAM5 (Morrison and Gettelman 2008; Gettelman et al. 2010); that is, RH values reach liquid saturation as long as liquid droplets coexist with ice particles, regardless of the small mass fraction of liquid phase being present. Note that this assumption is accurate for most of the liquid and mixed-phase samples (Figs. 12a-c and 12e-g), but as liquid mass fraction decreases to below 0.1 , it becomes unlikely that the incloud conditions can reach a steady-state condition close to liquid saturation when few droplets exist.
For liquid and mixed phases, all of the observations show increasing fractions of ISS and increasing magnitudes of maximum ISS with decreasing temperature, which agree relatively well with the simulations. Such increasing magnitudes of ISS are a result of the majority of liquid and mixed phases being around liquid saturation, which leads to higher RHi as temperature decreases based on the Clausius-Clapeyron equation.

In addition, two other model-observation differences are seen for ice phase. First, the simulations underestimate the occurrence frequencies of ice subsaturation. At $-10^{\circ}$ to $0^{\circ} \mathrm{C}$, the observations show $\sim 60 \%$ of ice phase being subsaturated, whereas CAMcollocated and CAM-domain show $\sim 25 \%$ and $\sim 10 \%$, respectively. The fact that simulations are characterized by lower IWC (Fig. 7g) combined with the lower frequencies of subsaturation for ice phase suggests that the simulations may underrepresent ice particles in subsaturated layers during sedimentation (as illustrated in Fig. 3), likely due to insufficient accretion rates and/or overamplified sublimation rates. Second, the simulations do not show any ISS greater than $10 \%$ for ice phase at $-40^{\circ}$ to $-30^{\circ} \mathrm{C}$ (Fig. 131), which accounts for $\sim 15 \%$ of the samples in all the observations. The lower frequency of high ISS at colder temperatures 
is likely affected by the RHi threshold for immersion nucleation of ice particles in the ice microphysics parameterization (Liu et al. 2007; Liu and Penner 2005).

\section{e. Vertical profiles of ice supersaturation}

Ice supersaturation is a key factor that directly affects ice particle growth, deposition, and sublimation, which is further examined in Fig. 14. Three cases are examined at temperatures below $0^{\circ} \mathrm{C}$ : ISS at low cloud fraction $(<0.1)$, ISS at high cloud fraction $(\geq 0.6)$, and non-ISS (i.e., RHi $\leq 100 \%$ ) at high cloud fraction $(\geq 0.6)$. Frequencies are either normalized by all samples (Figs. 14a-c) or normalized by the total number of the aforementioned three cases (Figs. 14d-f). Comparisons are only shown for the CAM-collocated data (different results for CAM-domain data are not shown), since ISS frequency is affected by local conditions such as vertical velocity, temperature, and existing hydrometeors.

Focusing on $-40^{\circ}$ to $0^{\circ} \mathrm{C}$, Obs-200s and CAMcollocated data show similar profiles of ISS at low cloud fraction with a peak frequency between $-15^{\circ}$ and $-10^{\circ} \mathrm{C}$. The simulation also shows a decreasing trend in ISS frequency at high cloud fraction with decreasing temperature, consistent with the observations. However, the simulation shows higher frequencies of ISS at high cloud fraction, which is likely due to the model assumption of liquid saturation for the fraction of the grid box where liquid and ice phases coexist, as discussed in section $3 \mathrm{~d}$.

For temperatures below $-40^{\circ} \mathrm{C}$, the CAM-collocated data significantly overestimate the frequencies of ISS by $0.05-0.75$ compared with the observations for cloud fractions $\geq 0.6$ (Fig. $14 \mathrm{~b}$ ). At temperatures below $-50^{\circ} \mathrm{C}$, the CAM-collocated data underestimate ISS frequency at cloud fractions $<0.1$. This result indicates that additional ISS needs to be allowed for clear-sky conditions rather than in-cloud conditions in CAM5 simulations at cirrus cloud regimes. The relative frequencies of these three cases further illustrate the increasing discrepancies between the observations and simulations with decreasing temperatures below $-40^{\circ} \mathrm{C}$ (Figs. 14d-f). Improvements are potentially needed for parameterizations of clear-sky ISS, ice nucleation condition, and water vapor deposition in clouds.

\section{Conclusions and implications for climate simulations over the Southern Ocean}

In this study, cloud microphysical properties over the Southern Ocean $\left(30^{\circ}-75^{\circ} \mathrm{S}, 50^{\circ}-92^{\circ} \mathrm{W}\right)$ are examined based on in situ airborne measurements, and are compared with two sets of CAM5 simulations: one is nudged by the reanalysis meteorological conditions and collocated with the aircraft flight track (CAM-collocated), and the other one is free-running (CAM-domain) and contains all the gridded data within the latitudinal, longitudinal, and pressure domain during the ORCAS campaign. The two simulations primarily produce comparable results (Figs. 4-13) (except for ISS frequency due to sensitivity to local thermodynamic and dynamical conditions), suggesting statistical robustness for the analyses conducted in this work when comparing localized samples with a larger set of samples.

Airborne measurements are averaged over various horizontal scales from $\sim 0.1$ to $50 \mathrm{~km}$, in order to provide a scale-aware comparison with GCM simulations. For the analyses of cloud phase occurrence frequency, $\mathrm{RH}$ PDFs and CFDs, and LWC/CWC ratios, the sensitivity to horizontal resolution is very low, which demonstrates the consistency of these results at various horizontal resolutions. Other microphysical properties (i.e., LWC, IWC, $\mathrm{Nc}_{\text {liq }}$, and $\mathrm{Nc}_{\text {ice }}$ ) show one to two orders of magnitude lower values when averaged over the entire scale that includes both in-cloud and clearsky conditions. These sensitivity tests demonstrate the applicability of using in situ observations to evaluate GCM simulations for cloud characteristics and RH distributions, which also help to guide future comparisons of datasets at various spatial resolutions.

Several main differences between simulations and observations are identified. Liquid and mixed phases are seen in Obs-1s data at low temperatures $\left(-40^{\circ}\right.$ to $-30^{\circ} \mathrm{C}$ ) with $3 \%$ and $4 \%$ frequencies, respectively, which are missing in the simulations. SLW droplets are frequently observed from $-20^{\circ}$ to $0^{\circ} \mathrm{C}$, consistent with previous observations that frequently reported SLW in this region (Morrison et al. 2011; Chubb et al. 2013; Huang et al. 2012b), while the simulations show higher liquid-phase and lower mixed-phase frequencies at this temperature range. Simulations also show higher (lower) LWC in liquid (mixed) phase, higher (lower) $\mathrm{Nc}_{\text {liq }}$ in liquid (mixed) phase, lower IWC in both ice and mixed phases, higher (lower) $\mathrm{Nc}_{\text {ice }}$ below (above) $-5^{\circ} \mathrm{C}$ in mixed phase, and lower (higher) LWC/CWC ratios below (above) $-5^{\circ} \mathrm{C}$ for the total in-cloud conditions. Biases of cloud microphysical properties vary with different cloud phases, indicating that future observational constraints may need to be specified for different phases. Processes of interest not only include the temperature function of phase partitioning such as that used in the shallow convection scheme of Park and Bretherton (2009) and tested by Kay et al. (2016a) and Frey and Kay (2018), but also include ice nucleation and vapor deposition rate during the WBF process as tested by Tan and Storelvmo (2016). 


\section{ISS \& Cld fret $<0.1$}

Relative difference (\%)

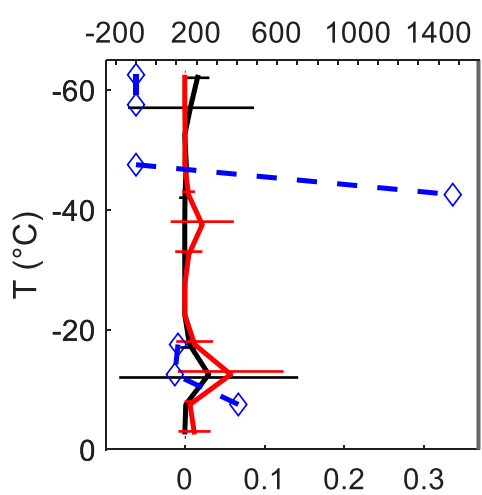

Occurrence frequency w.r.t. all data

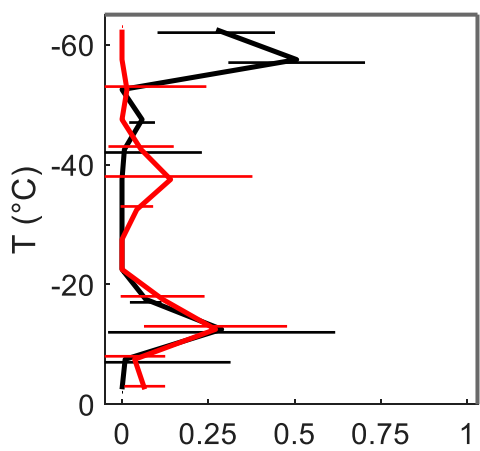

Occurrence frequency w.r.t. three conditions

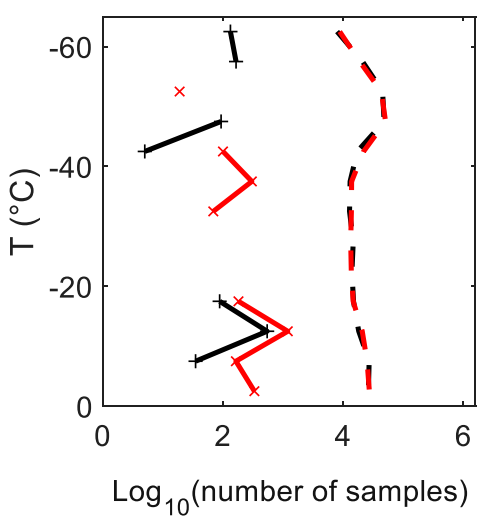

\section{ISS \& Cld fret $\geq 0.6$}

Relative difference (\%)

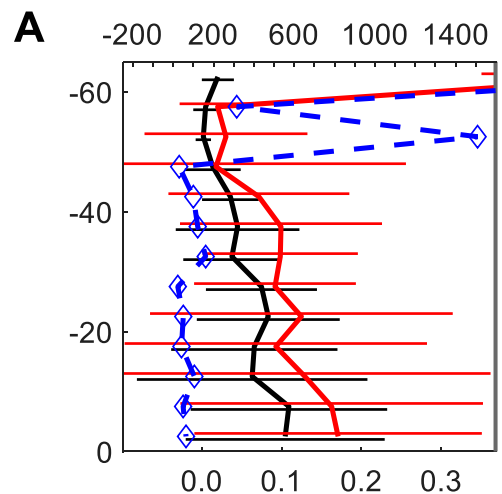

Occurrence frequency w.r.t. all data

D

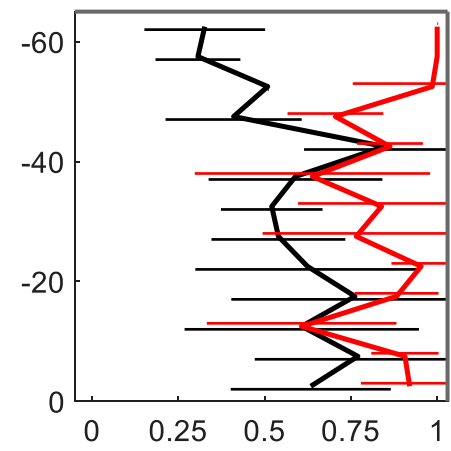

Occurrence frequency w.r.t. three conditions

G

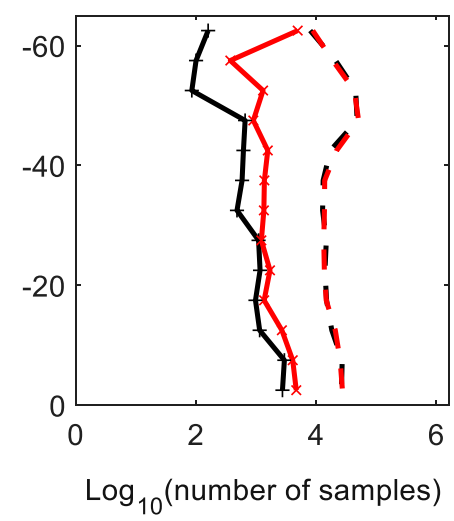

non-ISS \& Cld frct $\geq 0.6$

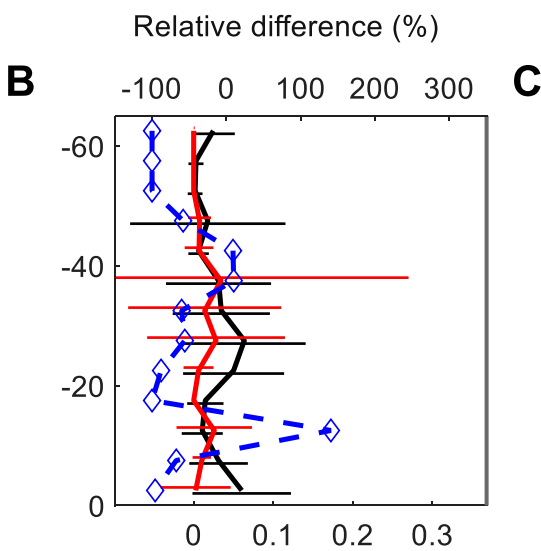

E

\section{Occurrence frequency} w.r.t. all data

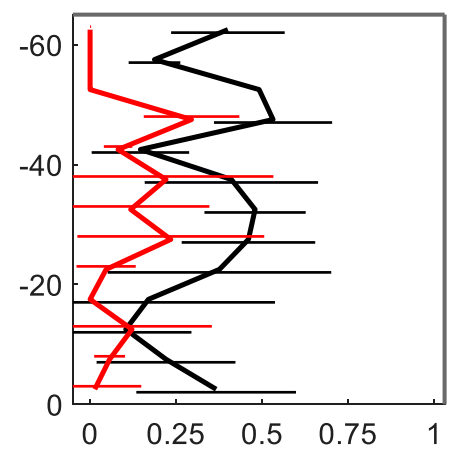

Occurrence frequency w.r.t. three conditions

H

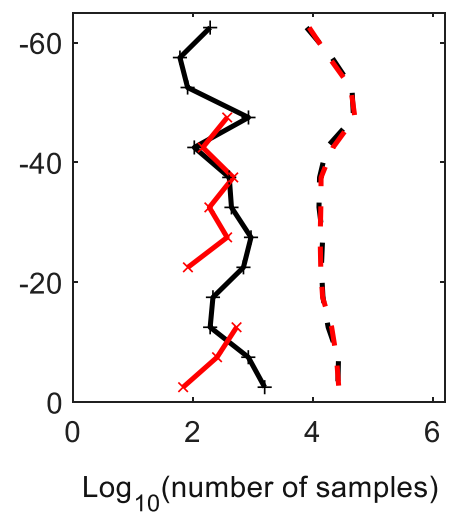

Obs-200s

CAM-colloc

$\diamond-\cdots($ CAM-colloc-Obs-200s)/Obs-200s $\times 100 \%$

FIG. 14. Vertical profiles for the occurrence frequencies of three cases: (left) ISS at cloud fraction $<0.1$, (center) ISS at cloud fraction $\geq 0.6$, and (right) non-ISS at cloud fraction $\geq 0.6$ for Obs-200s and CAM-collocated data. (a)-(c) Frequency normalized by the total number of samples at each $5^{\circ} \mathrm{C}$ intervals. Blue dashed lines show the relative differences (\%; upper abscissa): (CAM-collocated - Obs200s)/Obs-200s $\times 100 \%$. Horizontal whiskers represent the corrected sample standard deviation for 18 research flights. (d)-(f) Frequency normalized by the number of samples of these three conditions. (g)-(i) Number of samples for each specific condition in that column (solid lines with markers), and number of all the samples in each $5^{\circ} \mathrm{C}$ interval (dashed lines). 
A large amount of ice phase is observed at $-10^{\circ}$ to $0^{\circ} \mathrm{C}$, consistent with Huang et al. (2017), who found relatively high $\mathrm{Nc}_{\text {ice }}$ of small ice particles at $>-9^{\circ} \mathrm{C}$. In comparison, at $-5^{\circ}$ to $0^{\circ} \mathrm{C}$, simulations show smaller ice mass fraction (IWC/CWC) for total in-cloud conditions, potentially due to the insufficient growth of ice particles by deposition and/or accretion. For mixed phase, simulations show higher $\mathrm{Nc}_{\text {ice }}$ at $-40^{\circ}$ to $-5^{\circ} \mathrm{C}$ and lower $\mathrm{Nc}_{\text {ice }}$ at $-5^{\circ}$ to $0^{\circ} \mathrm{C}$ compared with the observations, with the former difference possibly due to ice nucleation parameterization and the latter difference possibly due to insufficient secondary ice production or missing INPs at warmer temperatures over the Southern Ocean. The lack of ice subsaturation in simulations is likely due to too fast removal of ice particles during sedimentation into subsaturated conditions.

In-cloud RH is frequently observed at liquid saturation for liquid and mixed phases. This feature can be a result of several processes, such as vapor diffusion from liquid to ice due to the WBF process, and/or updraft vertical velocity on the order of $0.1-1 \mathrm{~m} \mathrm{~s}^{-1}$ that can potentially sustain simultaneous growth of liquid droplets and ice particles (Korolev and Field 2008; Korolev 2007; Fan et al. 2011; Korolev 2008). The similarity among various scales of averaged observation datasets highlights the consistency of such findings when a sufficient amount of LWC exists (i.e., LWC/CWC > 0.1). However, larger deviations from liquid saturation are observed in ice phase (i.e., $\mathrm{LWC} / \mathrm{CWC} \leq 0.1$ ) at various scales. These results suggest that the assumption of liquid saturation for wherever liquid droplets exist (Morrison and Gettelman 2008) is not applicable when mass fraction of LWC is low, even for coexisting liquid droplets and ice particles on $\sim 100$-m scales. In addition, the increasing deviations from liquid saturation with increasing ice mass fraction imply that $\mathrm{RH}$ frequency distributions can serve as an indicator for estimating the dominant phase of cloud condensates (i.e., SLW droplets or ice particles).

Comparing RH distributions, simulations show smaller RH variability for partially cloudy conditions (cloud fraction of 0.1-0.9), and overestimate (underestimate) ISS frequencies for cloud fraction $\geq 0.6(<0.1)$ at $-67^{\circ}$ to $0^{\circ} \mathrm{C}\left(<-40^{\circ} \mathrm{C}\right)$. In addition, ice cloud fraction in CAM5 is parameterized by grid average RHi and other prescribed parameters (e.g., $\mathrm{RHi}_{\max }=1.1$ and $\left.\mathrm{RHi}_{\min }=0.8\right)($ Gettelman et al. 2010). In contrast, observations show larger variabilities of RHi at various cloud fractions, especially with higher frequencies of $\mathrm{RHi}>110 \%$ and $\mathrm{RHi}<90 \%$ at cloud fraction $\geq 0.1$ compared with simulations (Fig. 11), which in part casts doubt on the simplification of parameterizing ice cloud fraction as a function of the grid average RHi rather than local RHi. Previously, the lack of RH variability was found to be a main cause of missing clouds in CAM5 simulations (Wu et al. 2017), and the simulations often overlook water vapor spatial heterogeneities that were ubiquitously shown in observations (Diao et al. 2014). Since RH is a key parameter that links dynamical and thermodynamical conditions with cloud macro- and microphysical properties, improving the subgrid parameterization of $\mathrm{RH}$ not only is helpful for improving RH distributions, ISS frequencies, and ice cloud fraction, but also could be a viable approach to represent the impacts of subgrid-scale processes (e.g., eddies and turbulence) that are crucial for maintaining SLW (Field et al. 2014; Hill et al. 2014; Korolev and Field 2008) and calculating the lifetime of MPCs (Korolev and Mazin 2003). For future work, dynamical influences from vertical velocity, such as previously shown for Arctic and midlatitude MPCs (Solomon et al. 2011; Morrison et al. 2012; Korolev and Field 2008; Shupe et al. 2008; Morrison and Pinto 2005; Naud et al. 2006), warrant more detailed investigation over the Southern Ocean.

Acknowledgments. M. Diao acknowledges the support of NSF Grant AGS-1642291 and NSF Office of Polar Program (OPP) Grant 1744965. C. Wu acknowledges the National Key Research and Development Program of China (Grant 2017YFA0603503). X. Liu acknowledges the NSF Grant AGS-1642289 and DOE Atmospheric System Research Program (Grant DE-SC0014239). J. D'Alessandro acknowledges the support of John P. and Anna Monteverdi Scholarship. This work is based on part of the master's thesis work of J. D'Alessandro at San Jose State University (D'Alessandro 2018). The National Center for Atmospheric Research (NCAR) is sponsored by the National Science Foundation (NSF). The GV operations and cloud microphysics and state parameter instruments were supported by the NSF Lower Atmosphere Observing Facilities and NCAR Earth Observing Laboratory (EOL). The primary award supporting ORCAS science activities was NSF Polar Programs Grant 1501993. The NSF ORCAS campaign dataset is publicly available and can be accessed at http:// www.eol.ucar.edu/field_projects/orcas. The VCSEL hygrometer and water vapor measurements were supported by M. Diao and S. Beaton. Fast-2DC measurements received support from A. Bansemer and C. Webster. We thank the pilots, mechanics, technicians, scientists, software engineers, and project managers of the NCAR EOL Research Aviation Facility for their support in the field and in post-processing data. The authors also thank the three reviewers for their helpful comments and suggestions. 


\section{REFERENCES}

Abdul-Razzak, H., and S. J. Ghan, 2000: A parameterization of aerosol activation: 2. Multiple aerosol types. J. Geophys. Res., 105, 6837-6844, https://doi.org/10.1029/1999JD901161.

Ahn, E., Y. Huang, T. H. Chubb, D. Baumgardner, P. Isaac, M. de Hoog, S. T. Siems, and M. J. Manton, 2017: In situ observations of wintertime low-altitude clouds over the Southern Ocean. Quart. J. Roy. Meteor. Soc., 143, 1381-1394, https:// doi.org/10.1002/qj.3011.

Anderson, J. L., and Coauthors, 2004: The new GFDL global atmosphere and land model AM2-LM2: Evaluation with prescribed SST simulations. J. Climate, 17, 4641-4673, https:// doi.org/10.1175/JCLI-3223.1.

Baumgardner, D., and Coauthors, 2017: Cloud ice properties: In situ measurement challenges. Ice Formation and Evolution in Clouds and Precipitation: Measurement and Modeling Challenges, Meteor. Monogr., No. 58, Amer. Meteor. Soc., 9.1-9.23, doi:10.1175/AMSMONOGRAPHS-D-16-0011.1.

Bergeron, T., 1928: Über die dreidimensional verknüpfende Wetteranalyse. Geophys. Norv., 5, 1-111.

1935: On the physics of clouds and precipitation. Proces Verbaux l'Association Météorologie, International Union of Geodesy and Geophysics, 156-178.

Biter, C. J., J. E. Dye, D. Huffman, and W. D. King, 1987: The dropsize response of the CSIRO liquid water probe. J. Atmos. Oceanic Technol., 4, 359-367, https://doi.org/10.1175/15200426(1987)004<0359:TDSROT>2.0.CO;2.

Bodas-Salcedo, A., K. D. Williams, P. R. Field, and A. P. Lock, 2012: The surface downwelling solar radiation surplus over the Southern Ocean in the Met Office Model: The role of midlatitude cyclone clouds. J. Climate, 25, 7467-7486, https:// doi.org/10.1175/JCLI-D-11-00702.1.

, and Coauthors, 2014: Origins of the solar radiation biases over the Southern Ocean in CFMIP2 models. J. Climate, 27, 41-56, https://doi.org/10.1175/JCLI-D-13-00169.1.

, P. G. Hill, K. Furtado, K. D. Williams, P. R. Field, J. C. Manners, P. Hyder, and S. Kato, 2016: Large contribution of supercooled liquid clouds to the solar radiation budget of the Southern Ocean. J. Climate, 29, 4213-4228, https://doi.org/ 10.1175/JCLI-D-15-0564.1.

Brown, P. R. A., and P. N. Francis, 1995: Improved measurements of the ice water content in cirrus using a total-water probe. J. Atmos. Oceanic Technol., 12, 410-414, https://doi.org/ 10.1175/1520-0426(1995)012<0410:IMOTIW>2.0.CO;2.

Ceppi, P., M. D. Zelinka, and D. L. Hartmann, 2014: The response of the Southern Hemispheric eddy-driven jet to future changes in shortwave radiation in CMIP5. Geophys. Res. Lett., 41, 3244-3250, https://doi.org/10.1002/2014GL060043.

Cesana, G., and H. Chepfer, 2013: Evaluation of the cloud thermodynamic phase in a climate model using CALIPSOGOCCP. J. Geophys. Res. Atmos., 118, 7922-7937, https:// doi.org/10.1002/jgrd.50376.

—, D. E. Waliser, X. Jiang, and J.-L. F. Li, 2015: Multimodel evaluation of cloud phase transition using satellite and reanalysis data. J. Geophys. Res., 120, 7871-7892. https://doi.org/ 10.1002/2014JD022932.

_ - and Coauthors, 2016: Using in situ airborne measurements to evaluate three cloud phase products derived from CALIPSO. J. Geophys. Res., 121, 5788-5808, https://doi.org/10.1002/ 2015JD024334.

Cho, H.-M., S. L. Nasiri, and P. Yang, 2009: Application of CALIOP measurements to the evaluation of cloud phase derived from
MODIS infrared channels. J. Appl. Meteor. Climatol., 48 , 2169-2180, https://doi.org/10.1175/2009JAMC2238.1.

Chubb, T. H., J. B. Jensen, S. T. Siems, and M. J. Manton, 2013: In situ observations of supercooled liquid clouds over the Southern Ocean during the HIAPER Pole-to-Pole Observation campaigns. Geophys. Res. Lett., 40, 5280-5285, https://doi.org/10.1002/grl.50986.

Chylek, P., and C. Borel, 2004: Mixed phase cloud water/ice structure from high spatial resolution satellite data. Geophys. Res. Lett., 31, L14104, https://doi.org/10.1029/2004GL020428.

_, S. Robinson, M. K. Dubey, M. D. King, Q. Fu, and W. B. Clodius, 2006: Comparison of near-infrared and thermal infrared cloud phase detections. J. Geophys. Res., 111, D20203, https://doi.org/10.1029/2006JD007140.

Costa, A., and Coauthors, 2017: Classification of Arctic, midlatitude and tropical clouds in the mixed-phase temperature regime. Atmos. Chem. Phys., 17, 12 219-12 238, https://doi.org/ 10.5194/acp-17-12219-2017.

Cotton, W. R., G. J. Tripoli, R. M. Rauber, and E. A. Mulvihill, 1986: Numerical simulation of the effects of varying ice crystal nucleation rates and aggregation processes on orographic snowfall. J. Climate Appl. Meteor., 25, 1658-1680, https://doi.org/ 10.1175/1520-0450(1986)025<1658:NSOTEO > 2.0.CO;2.

D'Alessandro, J., 2018: Cloud microphysical properties based on airborne in situ observations and evaluation of a weather forecasting model and a global climate model. M.S. thesis, Dept. of Meteorology and Climate Science, San Jose State University, 78 pp., https://scholarworks.sjsu.edu/etd_theses/ 4935.

DeMott, P. J., and Coauthors, 2010: Predicting global atmospheric ice nuclei distributions and their impacts on climate. Proc. Natl. Acad. Sci. USA, 107, 11217-11222, https://doi.org/ 10.1073/pnas.0910818107.

Diao, M., L. Jumbam, J. Sheffield, E. F. Wood, and M. A. Zondlo, 2013: Validation of AIRS/AMSU-A water vapor and temperature data with in situ aircraft observations from the surface to UT/LS from $87^{\circ} \mathrm{N}-67^{\circ} \mathrm{S}$. J. Geophys. Res. Atmos., 118, 6816-6836, https://doi.org/10.1002/jgrd.50483.

—, M. A. Zondlo, A. J. Heymsfield, L. M. Avallone, M. E. Paige, S. P. Beaton, T. Campos, and D. C. Rogers, 2014: Cloud-scale ice-supersaturated regions spatially correlate with high water vapor heterogeneities. Atmos. Chem. Phys., 14, 2639-2656, https://doi.org/10.5194/acp-14-2639-2014.

Donner, L. J., and Coauthors, 2011: The dynamical core, physical parameterizations, and basic simulation characteristics of the atmospheric component AM3 of the GFDL global coupled model CM3. J. Climate, 24, 3484-3519, https://doi.org/10.1175/ 2011JCLI3955.1.

Fan, J., S. Ghan, M. Ovchinnikov, X. Liu, P. J. Rasch, and A. Korolev, 2011: Representation of Arctic mixed-phase clouds and the Wegener-Bergeron-Findeisen process in climate models: Perspectives from a cloud-resolving study. J. Geophys. Res., 116, D00T07, https://doi.org/10.1029/ 2010JD015375.

Field, P. R., R. J. Hogan, P. R. A. Brown, A. J. Illingworth, T. W. Choularton, P. H. Kaye, E. Hirst, and R. Greenaway, 2004: Simultaneous radar and aircraft observations of mixed-phase cloud at the $100 \mathrm{~m}$ scale. Quart. J. Roy. Meteor. Soc., 130, 1877-1904, https://doi.org/10.1256/qj.03.102.

- A. A. Hill, K. Furtado, and A. Korolev, 2014: Mixed-phase clouds in a turbulent environment. Part 2: Analytic treatment. Quart. J. Roy. Meteor. Soc., 140, 870-880, https://doi.org/ 10.1002/qj.2175. 
Findeisen, W., 1938: Kolloid-meteorologische Vorgänge bei Neiderschlags-bildung. Meteor. Z., 55, 121-133.

_ 1940: On the origin of thunderstorm electricity. Meteor. Z., 57, 201-215.

Forbes, R. M., and M. Ahlgrimm, 2014: On the representation of high-latitude boundary layer mixed-phase cloud in the ECMWF global model. Mon. Wea. Rev., 142, 3425-3445, https://doi.org/10.1175/MWR-D-13-00325.1.

Frey, W. R., and J. E. Kay, 2018: The influence of extratropical cloud phase and amount feedbacks on climate sensitivity. Climate Dyn., 50, 3097-3116, https://doi.org/10.1007/s00382017-3796-5.

Fu, Q., and S. Hollars, 2004: Testing mixed-phase cloud water vapor parameterizations with SHEBA/FIRE-ACE observations. J. Atmos. Sci., 61, 2083-2091, https://doi.org/ 10.1175/1520-0469(2004)061<2083:TMCWVP>2.0.CO;2.

Gayet, J.-F., and Coauthors, 2006: Microphysical and optical properties of midlatitude cirrus clouds observed in the Southern Hemisphere during INCA. Quart. J. Roy. Meteor. Soc., 132, 2719-2748, https://doi.org/10.1256/qj.05.162.

Gettelman, A., and H. Morrison, 2015: Advanced two-moment bulk microphysics for global models. Part I: Off-line tests and comparison with other schemes. J. Climate, 28, 1268-1287, https://doi.org/10.1175/JCLI-D-14-00102.1.

— feedback. Curr. Climate Change Rep., 2, 179-189, https:// doi.org/10.1007/s40641-016-0052-8.

— - E. J. Fetzer, A. Eldering, and F. W. Irion, 2006: The global distribution of supersaturation in the upper troposphere from the Atmospheric Infrared Sounder. J. Climate, 19, 6089-6103, https://doi.org/10.1175/JCLI3955.1.

_ - and Coauthors, 2010: Global simulations of ice nucleation and ice supersaturation with an improved cloud scheme in the Community Atmosphere Model. J. Geophys. Res., 115, D18216, https://doi.org/10.1029/2009JD013797.

Goff, J. A., and S. Gratch, 1946: Low-pressure properties of water from $-160^{\circ}$ to $212^{\circ}$ F. Trans. Amer. Soc. Heat Air-Cond. Eng. 52, 95-122.

Goloub, P., M. Herman, H. Chepfer, J. Riedi, G. Brogniez, P. Couvert, and G. Séze, 2000: Cloud thermodynamical phase classification from the POLDER spaceborne instrument. J. Geophys. Res., 105, 14747-14 759, https://doi.org/10.1029/ 1999JD901183.

Govekar, P. D., C. Jakob, and J. Catto, 2014: The relationship between clouds and dynamics in Southern Hemisphere extratropical cyclones in the real world and a climate model. J. Geophys. Res., 119, 6609-6628, https://doi.org/10.1002/ 2013JD020699.

Hill, A. A., P. R. Field, K. Furtado, A. Korolev, and B. J. Shipway, 2014: Mixed-phase clouds in a turbulent environment. Part 1: Large-eddy simulation experiments. Quart. J. Roy. Meteor. Soc., 140, 855-869, https://doi.org/10.1002/qj.2177.

Hoskins, B. J., and K. I. Hodges, 2005: A new perspective on Southern Hemisphere storm tracks. J. Climate, 18, 4108-4129, https://doi.org/10.1175/JCLI3570.1.

$\mathrm{Hu}$, Y., and Coauthors, 2009: CALIPSO/CALIOP cloud phase discrimination algorithm. J. Atmos. Oceanic Technol., 26, 2293-2309, https://doi.org/10.1175/2009JTECHA1280.1.

— - S. Rodier, K. Xu, W. Sun, J. Huang, B. Lin, P. Zhai, and D. Josset, 2010: Occurrence, liquid water content, and fraction of supercooled water clouds from combined CALIOP/IIR/ MODIS measurements. J. Geophys. Res., 115, D00H34, https://doi.org/10.1029/2009JD012384.
Huang, Y., S. T. Siems, M. J. Manton, L. B. Hande, and J. M. Haynes, 2012a: The Structure of low-altitude clouds over the Southern Ocean as seen by CloudSat. J. Climate, 25, 25352546, https://doi.org/10.1175/JCLI-D-11-00131.1.

,,---1, A. Protat, and J. Delanoë, 2012b: A study on the low-altitude clouds over the Southern Ocean using the DARDAR-MASK. J. Geophys. Res., 117, D18204, https:// doi.org/10.1029/2012JD017800.

,,,--- and G. Thompson, 2014: An evaluation of WRF simulations of clouds over the Southern Ocean with A-Train observations. Mon. Wea. Rev., 142, 647-667, https://doi.org/ 10.1175/MWR-D-13-00128.1.

, C. N. Franklin, S. T. Siems, M. J. Manton, T. Chubb, A. Lock, S. Alexander, and A. Klekociuk, 2015: Evaluation of boundary-layer cloud forecasts over the Southern Ocean in a limited-area numerical weather prediction system using in situ, space-borne and ground-based observations. Quart. J. Roy. Meteor. Soc., 141, 2259-2276, https://doi.org/10.1002/ qj.2519.

, T. Chubb, D. Baumgardner, M. DeHoog, S. T. Siems, and M. J. Manton, 2017: Evidence for secondary ice production in Southern Ocean open cellular convection. Quart. J. Roy. Meteor. Soc., 143, 1685-1703, https://doi.org/10.1002/qj.3041.

Jensen, J. B., S. Lee, P. B. Krummel, J. Katzfey, and D. Gogoasa, 2000: Precipitation in marine cumulus and stratocumulus: Part I: Thermodynamic and dynamic observations of closed cell circulations and cumulus bands. Atmos. Res., 54, 117-155, https://doi.org/10.1016/S0169-8095(00)00040-5.

Kahn, B. H., A. Gettelman, E. J. Fetzer, A. Eldering, and C. K. Liang, 2009: Cloudy and clear-sky relative humidity in the upper troposphere observed by the A-Train. J. Geophys. Res., 114, D00H02, https://doi.org/10.1029/2009JD011738.

S. L. Nasiri, M. M. Schreier, and B. A. Baum, 2011: Impacts of subpixel cloud heterogeneity on infrared thermodynamic phase assessment. J. Geophys. Res., 116, D20201, https:// doi.org/10.1029/2011JD015774.

Kay, J. E., and Coauthors, 2012: Exposing global cloud biases in the Community Atmosphere Model (CAM) using satellite observations and their corresponding instrument simulators. J. Climate, 25, 5190-5207, https://doi.org/10.1175/JCLI-D-1100469.1.

, and Coauthors, 2016a: Global climate impacts of fixing the Southern Ocean shortwave radiation bias in the Community Earth System Model (CESM). J. Climate, 29, 4617-4636, https://doi.org/10.1175/JCLI-D-15-0358.1.

, L. Bourdages, N. B. Miller, A. Morrison, V. Yettella, H. Chepfer, and B. Eaton, 2016b: Evaluating and improving cloud phase in the Community Atmosphere Model version 5 using spaceborne lidar observations. J. Geophys. Res., 121, 4162-4176, https://doi.org/10.1002/2015JD024699.

King, W. D., D. A. Parkin, and R. J. Handsworth, 1978: A hot-wire liquid water device having fully calculable response characteristics. J. Appl. Meteor., 17, 1809-1813, https://doi.org/ 10.1175/1520-0450(1978)017<1809:AHWLWD>2.0.CO;2.

Komurcu, M., and Coauthors, 2014: Intercomparison of the cloud water phase among global climate models. J. Geophys. Res. Atmos., 119, 3372-3400, https://doi.org/10.1002/2013JD021119.

Korolev, A., 2007: Limitations of the Wegener-Bergeron-Findeisen mechanism in the evolution of mixed-phase clouds. J. Atmos. Sci., 64, 3372-3375, https://doi.org/10.1175/JAS4035.1.

2008: Rates of phase transformations in mixed-phase clouds. Quart. J. Roy. Meteor. Soc., 134, 595-608, https://doi.org/ 10.1002/qj.230. 
, and I. P. Mazin, 2003: Supersaturation of water vapor in clouds. J. Atmos. Sci., 60, 2957-2974, https://doi.org/10.1175/ 1520-0469(2003)060<2957:SOWVIC >2.0.CO;2.

—, and G. A. Isaac, 2006: Relative humidity in liquid, mixedphase, and ice clouds. J. Atmos. Sci., 63, 2865-2880, https:// doi.org/10.1175/JAS3784.1.

— , and P. R. Field, 2008: The effect of dynamics on mixed-phase clouds: theoretical considerations. J. Atmos. Sci., 65, 66-86, https://doi.org/10.1175/2007JAS2355.1.

_ and G. A. Isaac, 2008: The effect of spatial averaging on the relative humidity and phase composition of clouds. 2008 Int. Conf. on Clouds and Precipitation, Cancun, Mexico, ICCP, http://cabernet.atmosfcu.unam.mx/ICCP-2008/abstracts/Program_ on_line/Poster_01/Korolev\&Isaac_extended.pdf.

,-- , S. G. Cober, J. W. Strapp, and J. Hallett, 2003: Microphysical characterization of mixed-phase clouds. Quart. J. Roy. Meteor. Soc., 129, 39-65, https://doi.org/10.1256/ qj.01.204.

— challenges. Ice Formation and Evolution in Clouds and Precipitation: Measurement and Modeling Challenges, Meteor. Monogr., No. 58, Amer. Meteor. Soc., 5.1-5.50, https://doi.org/ 10.1175/AMSMONOGRAPHS-D-17-0001.1.

Krämer, M., and Coauthors, 2009: Ice supersaturations and cirrus cloud crystal numbers. Atmos. Chem. Phys., 9, 3505-3522, https://doi.org/10.5194/acp-9-3505-2009.

Lamarque, J.-F., and Coauthors, 2012: CAM-chem: Description and evaluation of interactive atmospheric chemistry in the Community Earth System Model. Geosci. Model Dev., 5, 369411, https://doi.org/10.5194/gmd-5-369-2012.

Lamquin, N., C. J. Stubenrauch, K. Gierens, U. Burkhardt, and H. Smit, 2012: A global climatology of upper-tropospheric ice supersaturation occurrence inferred from the Atmospheric Infrared Sounder calibrated by MOZAIC. Atmos. Chem. Phys., 12, 381-405, https://doi.org/10.5194/acp-12-381-2012.

Lawson, R. P., and A. Gettelman, 2014: Impact of Antarctic mixedphase clouds on climate. Proc. Natl. Acad. Sci. USA, 111, 18156-18161, https://doi.org/10.1073/pnas.1418197111.

Li, J.-L. F., D. E. Waliser, G. Stephens, S. Lee, T. L'Ecuyer, S. Kato, N. Loeb, and H.-Y. Ma, 2013: Characterizing and understanding radiation budget biases in CMIP3/CMIP5 GCMs, contemporary GCM, and reanalysis. J. Geophys. Res. Atmos., 118, 8166-8184, https://doi.org/10.1002/jgrd.50378.

Li, Z.-X., and H. Le Treut, 1992: Cloud-radiation feedbacks in a general circulation model and their dependence on cloud modelling assumptions. Climate Dyn., 7, 133-139, https:// doi.org/10.1007/BF00211155.

Lin, S.-J., 2004: A "vertically Lagrangian" finite-volume dynamical core for global models. Mon. Wea. Rev., 132, 2293-2307, https:// doi.org/10.1175/1520-0493(2004)132<2293:AVLFDC>2.0.CO;2.

Liu, X., and J. E. Penner, 2005: Ice nucleation parameterization for global models. Meteor. Z., 14, 499-514, https://doi.org/10.1127/ 0941-2948/2005/0059.

,-- , S. J. Ghan, and M. Wang, 2007: Inclusion of ice microphysics in the NCAR Community Atmospheric Model version 3 (CAM3). J. Climate, 20, 4526-4547, https://doi.org/ 10.1175/JCLI4264.1.

— , and Coauthors, 2011: Testing cloud microphysics parameterizations in NCAR CAM5 with ISDAC and M-PACE observations. J. Geophys. Res., 116, D00T11, https://doi.org/ 10.1029/2011JD015889.

_ aerosols in climate models: description and evaluation in the
Community Atmosphere Model CAM5. Geosci. Model Dev., 5, 709-739, https://doi.org/10.5194/gmd-5-709-2012.

Matus, A. V., and T. S. L'Ecuyer, 2017: The role of cloud phase in Earth's radiation budget. J. Geophys. Res. Atmos., 122, 25592578, https://doi.org/10.1002/2016JD025951.

McCoy, D. T., D. L. Hartmann, and D. P. Grosvenor, 2014a: Observed Southern Ocean cloud properties and shortwave reflection. Part I: Calculation of SW flux from observed cloud properties. J. Climate, 27, 8836-8857, https://doi.org/10.1175/ JCLI-D-14-00287.1.

,-- , and,$- 2014 \mathrm{~b}$ : Observed Southern Ocean cloud properties and shortwave reflection. Part II: Phase changes and low cloud feedback. J. Climate, 27, 8858-8868, https:// doi.org/10.1175/JCLI-D-14-00288.1.

_- I. Tan, D. L. Hartmann, M. D. Zelinka, and T. Storelvmo, 2016: On the relationships among cloud cover, mixed-phase partitioning, and planetary albedo in GCMs. J. Adv. Model. Earth Syst., 8, 650-668, https://doi.org/10.1002/2015MS000589.

McFarquhar, G. M., G. Zhang, M. R. Poellot, G. L. Kok, R. McCoy, T. Tooman, A. Fridlind, and A. J. Heymsfield, 2007: Ice properties of single-layer stratocumulus during the Mixed-Phase Arctic Cloud Experiment: 1. Observations. J. Geophys. Res., 112, D24201, https://doi.org/10.1029/ 2007JD008633.

Meyers, M. P., P. J. DeMott, and W. R. Cotton, 1992: New primary ice-nucleation parameterizations in an explicit cloud model. J. Appl. Meteor., 31, 708-721, https://doi.org/10.1175/15200450(1992)031<0708:NPINPI>2.0.CO;2.

Mitchell, J. F. B., C. A. Senior, and W. J. Ingram, 1989: $\mathrm{CO}_{2}$ and climate: A missing feedback? Nature, 341, 132-134, https:// doi.org/10.1038/341132a0.

Morrison, A. E., S. T. Siems, M. J. Manton, and A. Nazarov, 2010: A modeling case study of mixed-phase clouds over the Southern Ocean and Tasmania. Mon. Wea. Rev., 138, 839-862, https://doi.org/10.1175/2009MWR3011.1.

,-- , and 2011: A three-year climatology of cloud-top phase over the Southern Ocean and North Pacific. J. Climate, 24, 2405-2418, https://doi.org/10.1175/2010JCLI3842.1.

Morrison, H., and J. O. Pinto, 2005: Mesoscale modeling of springtime Arctic mixed-phase stratiform clouds using a new two-moment bulk microphysics scheme. J. Atmos. Sci., 62 , 3683-3704, https://doi.org/10.1175/JAS3564.1.

_ cloud microphysics scheme in the Community Atmosphere Model, version 3 (CAM3). Part I: Description and numerical tests. J. Climate, 21, 3642-3659, https://doi.org/10.1175/ 2008JCLI2105.1.

— - G. de Boer, G. Feingold, J. Harrington, M. D. Shupe, and K. Sulia, 2012: Resilience of persistent Arctic mixed-phase clouds. Nat. Geosci., 5, 11-17, https://doi.org/10.1038/ ngeo1332.

Murphy, D. M., and T. Koop, 2005: Review of the vapour pressures of ice and supercooled water for atmospheric applications. Quart. J. Roy. Meteor. Soc., 131, 1539-1565, https://doi.org/ 10.1256/qj.04.94.

Nasiri, S. L., and B. H. Kahn, 2008: Limitations of bispectral infrared cloud phase determination and potential for improvement. J. Appl. Meteor. Climatol., 47, 2895-2910, https:// doi.org/10.1175/2008JAMC1879.1.

Naud, C. M., A. D. Del Genio, and M. Bauer, 2006: Observational constraints on the cloud thermodynamic phase in midlatitude storms. J. Climate, 19, 5273-5288, https://doi.org/10.1175/ JCLI3919.1. 
Neale, R. B., and Coauthors, 2012: Description of the NCAR Community Atmosphere Model (CAM 5.0), NCAR/TN486+STR, 274 pp., http://www.cesm.ucar.edu/models/cesm1.0/ cam/docs/description/cam5 desc.pdf.

Ovarlez, J., J.-F. Gayet, K. Gierens, J. Ström, H. Ovarlez, F. Auriol, R. Busen, and U. Schumann, 2002: Water vapour measurements inside cirrus clouds in Northern and Southern Hemispheres during INCA. Geophys. Res. Lett., 29, 1813, https:// doi.org/10.1029/2001GL014440.

Park, S., and C. S. Bretherton, 2009: The University of Washington shallow convection and moist turbulence schemes and their impact on climate simulations with the Community Atmosphere Model. J. Climate, 22, 3449-3469, https://doi.org/ 10.1175/2008JCLI2557.1.

,-- , and P. J. Rasch, 2014: Integrating cloud processes in the Community Atmosphere Model, version 5. J. Climate, 27, 6821-6856, https://doi.org/10.1175/JCLI-D-14-00087.1.

Rauber, R. M., and A. Tokay, 1991: An explanation for the existence of supercooled water at the top of cold clouds. J. Atmos. Sci., 48, 1005-1023, https://doi.org/10.1175/1520-0469(1991) 048<1005:AEFTEO > 2.0.CO;2.

Riedi, J., P. Goloub, and R. T. Marchand, 2001: Comparison of POLDER cloud phase retrievals to active remote sensors measurements at the ARM SGP site. Geophys. Res. Lett., 28 , 2185-2188, https://doi.org/10.1029/2000GL012758.

— , and Coauthors, 2010: Cloud thermodynamic phase inferred from merged POLDER and MODIS data. Atmos. Chem Phys., 10, 11 851-11 865, https://doi.org/10.5194/acp-10-118512010.

Rotstayn, L. D., B. F. Ryan, and J. J. Katzfey, 2000: A scheme for calculation of the liquid fraction in mixed-phase stratiform clouds in large-scale models. Mon. Wea. Rev., 128, 1070-1088, https:// doi.org/10.1175/1520-0493(2000)128<1070:ASFCOT >2.0.CO;2.

Shupe, M. D., and J. M. Intrieri, 2004: Cloud radiative forcing of the Arctic surface: The influence of cloud properties, surface albedo, and solar zenith angle. J. Climate, 17, 616-628, https:// doi.org/10.1175/1520-0442(2004)017<0616:CRFOTA >2.0.CO;2.

_ , P. Kollias, P. O. G. Persson, and G. M. McFarquhar, 2008: Vertical motions in Arctic mixed-phase stratiform clouds. J. Atmos. Sci., 65, 1304-1322, https://doi.org/10.1175/ 2007JAS2479.1.

Solomon, A., M. D. Shupe, P. O. G. Persson, and H. Morrison, 2011: Moisture and dynamical interactions maintaining decoupled Arctic mixed-phase stratocumulus in the presence of a humidity inversion. Atmos. Chem. Phys., 11, 10127 10148, https://doi.org/10.5194/acp-11-10127-2011.

Spichtinger, P., K. Gierens, and W. Read, 2003: The global distribution of ice-supersaturated regions as seen by the Microwave Limb Sounder. Quart. J. Roy. Meteor. Soc., 129, 3391-3410, https://doi.org/10.1256/qj.02.141.
Stephens, B. B., 2017: ORCAS Merge Products, version 1.0. UCAR/NCAR-Earth Observing Laboratory, accessed 10 January 2019, https://doi.org/10.5065/D6SB445X.

- , and Coauthors, 2018: The $\mathrm{O}_{2} / \mathrm{N}_{2}$ Ratio and $\mathrm{CO}_{2}$ Airborne Southern Ocean Study. Bull. Amer. Meteor. Soc., 99, 381-402, https://doi.org/10.1175/BAMS-D-16-0206.1.

Sun, Z., and K. P. Shine, 1994: Studies of the radiative properties of ice and mixed-phase clouds. Quart. J. Roy. Meteor. Soc., 120, 111-137, https://doi.org/10.1002/qj.49712051508.

Tan, I., and T. Storelvmo, 2016: Sensitivity study on the influence of cloud microphysical parameters on mixed-phase cloud thermodynamic phase partitioning in CAM5. J. Atmos. Sci., 73, 709-728, https://doi.org/10.1175/JAS-D-15-0152.1.

,-- , and M. D. Zelinka, 2016: Observational constraints on mixed-phase clouds imply higher climate sensitivity. Science, 352, 224-227, https://doi.org/10.1126/science.aad5300.

Thompson, D. R., B. H. Kahn, R. O. Green, S. A. Chien, E. M. Middleton, and D. Q. Tran, 2018: Global spectroscopic survey of cloud thermodynamic phase at high spatial resolution, 2005-2015. Atmos. Meas. Tech., 11, 1019-1030, https://doi.org/ 10.5194/amt-11-1019-2018.

Trenberth, K. E., and J. T. Fasullo, 2010: Simulation of presentday and twenty-first-century energy budgets of the Southern Oceans. J. Climate, 23, 440-454, https://doi.org/10.1175/ 2009JCLI3152.1.

Tsushima, Y., and Coauthors, 2006: Importance of the mixed-phase cloud distribution in the control climate for assessing the response of clouds to carbon dioxide increase: A multi-model study. Climate Dyn., 27, 113-126, https://doi.org/10.1007/s00382-006-0127-7.

Wang, Y., D. Zhang, X. Liu, and Z. Wang, 2018: Distinct contributions of ice nucleation, large-scale environment, and shallow cumulus detrainment to cloud phase partitioning with NCAR CAM5. J. Geophys. Res. Atmos., 123, 1132-1154, https://doi.org/10.1002/2017JD027213.

Wegener, A., 1911: Thermodynamik der Atmosphäre. J. A. Barth, 331 pp. Wu, C., X. Liu, M. Diao, K. Zhang, A. Gettelman, Z. Lu, J. E. Penner, and Z. Lin, 2017: Direct comparisons of ice cloud macro- and microphysical properties simulated by the Community Atmosphere Model version 5 with HIPPO aircraft observations. Atmos. Chem. Phys., 17, 4731-4749, https://doi.org/ 10.5194/acp-17-4731-2017.

Zhang, K., and Coauthors, 2014: Technical note: On the use of nudging for aerosol-climate model intercomparison studies. Atmos. Chem. Phys., 14, 8631-8645, https://doi.org/10.5194/ acp-14-8631-2014.

Zondlo, M. A., M. E. Paige, S. M. Massick, and J. A. Silver, 2010: Vertical cavity laser hygrometer for the National Science Foundation Gulfstream-V aircraft. J. Geophys. Res., 115, D20309, https://doi.org/10.1029/2010JD014445. 